Article

\title{
Areal-Averaged Spectral Surface Albedo from Ground-Based Transmission Data Alone: Toward an Operational Retrieval
}

\author{
Evgueni Kassianov ${ }^{1, *}$, James Barnard ${ }^{1}$, Connor Flynn ${ }^{1}$, Laura Riihimaki ${ }^{1}$, Joseph Michalsky ${ }^{2}$ \\ and Gary Hodges ${ }^{3}$
}

1 Pacific Northwest National Laboratory, Richland, WA 99352, USA;

E-Mails: James.Barnard@pnnl.gov (J.B.); Connor.Flynn@pnnl.gov (C.F.);

Laura.Riihimaki@pnnl.gov (L.R.)

2 NOAA/Earth System Research Laboratory, Boulder, CO 80305, USA;

E-Mail: Joseph.Michalsky@noaa.gov

3 University of Colorado/CIRES, Boulder, CO 80309, USA; E-Mail: Gary.Hodges@noaa.gov

* Author to whom correspondence should be addressed; E-Mail: Evgueni.Kassianov@pnnl.gov; Tel.: +1-509-372-6535; Fax: +1-509-375-6448.

Received: 13 June 2014; in revised form: 12 August 2014 / Accepted: 12 August 2014 /

Published: 22 August 2014

\begin{abstract}
We present here a simple retrieval of the areal-averaged spectral surface albedo using only ground-based measurements of atmospheric transmission under fully overcast conditions. Our retrieval is based on a one-line equation. The feasibility of our retrieval for routine determinations of albedo is demonstrated for different landscapes with various degrees of heterogeneity using three sets of measurements: (1) spectral atmospheric transmission from the Multi-Filter Rotating Shadowband Radiometer (MFRSR) at five wavelengths $(415,500,615,673$, and $870 \mathrm{~nm})$; (2) tower-based measurements of local surface albedo at the same wavelengths; and (3) areal-averaged surface albedo at four wavelengths (470, 560, 670 and $860 \mathrm{~nm}$ ) from collocated and coincident Moderate Resolution Imaging Spectroradiometer (MODIS) observations. These integrated datasets cover both temporally long (2008-2013) and short (April-May 2010) periods at the Atmospheric Radiation Measurement (ARM) Southern Great Plains site and the National Oceanic and Atmospheric Administration (NOAA) Table Mountain site, respectively. The calculated root mean square error (RMSE), defined here as the root mean squared difference between the MODIS-derived surface albedo and the retrieved areal-averaged albedo, is quite small (RMSE $\leq 0.015)$ and comparable with that obtained previously by other investigators for the shortwave broadband albedo. Good agreement between
\end{abstract}


tower-based measurements of daily-averaged surface albedo for completely overcast and non-overcast conditions is also demonstrated.

Keywords: Multi-Filter Rotating Shadowband Radiometer (MFRSR); tower-based measurements; Moderate Resolution Imaging Spectroradiometer (MODIS) observations; atmospheric transmission; areal-averaged and local surface albedo; spectral and seasonal variability; ARM Southern Great Plains (SGP) site; NOAA Table Mountain site

\section{Introduction}

Albedo, defined as a ratio of the upwelling irradiance from a surface over the downwelling irradiance reaching that surface, plays an extremely important role in the Earth's radiation balance [1,2]. To estimate the broadband and/or spectral surface albedo, both tower-based solar radiation measurements $[3,4]$ and remote sensing methods $[5,6]$ have been used. Although the amount and quality of airborne and satellite data with large spatial coverage have improved substantially over the last several decades [7,8], there remain well-known uncertainties associated with surface albedo retrievals from aircraft and space [9-11]. These uncertainties mostly originate from the lack of direct measurements of solar radiation incident on the surface. On the other hand, tower-based observations, which measure both incident and reflected components, provide values of the local surface albedo with high temporal resolution. However, these measurements suffer from limited spatial coverage and uneven spatial distribution [12]. Given the importance of obtaining and understanding temporal and spatial changes of surface albedo [13], there is a clear need to improve and extend surface albedo estimates.

In contrast to limited tower-based data, ground-based measurements of downwelling irradiances (in the absence of towers) are abundant and therefore have much larger spatial coverage. These measurements have been used extensively for retrieving optical and microphysical properties of overcast clouds, such as cloud optical depth $(\tau)$ and droplet effective radius $\left(r_{e}\right)$. The retrieval of these two important cloud parameters from irradiance measurements alone requires irradiance measurements at two wavelengths, one in the visible and the other in the near-infrared spectral range [14,15]. The conversion of such dual-channel measurements into cloud parameters ( $\tau$ and $r_{e}$ ) commonly involves radiative transfer (RT) calculations and assumed/measured spectrally resolved values of the surface albedo. Alternatively, the traditional dual-channel methods can be applied for simultaneously estimating $\tau$ and surface albedo for an assumed $r_{e}$. In particular, Ricchiazzi et al. [16] have introduced such a possibility using spectral solar irradiance measurements and detailed RT calculations.

Here, we revisit this possibility using a simple expression [17], that analytically links the surface albedo $(A)$, asymmetry factor $(g)$ and $\tau$ with measured atmospheric transmission under overcast conditions. Note that $\tau$ is inversely related to $r_{e}$ for fixed liquid water path [18,19]. (A lively picture of cloud optical properties and a description of simple analytical and highly sophisticated numerical RT methods are found in [19]). Originally, this semi-empirical expression was used for estimating $\tau$ at a single wavelength $(415 \mathrm{~nm})$, where the surface albedo is small and depends only weakly on the type of surface (e.g., in the absence of snow and ice; see [20]). In this paper, we apply the Barnard et al. [17] 
expression to estimate areal-averaged surface albedo using the general framework behind conventional dual-channel methods.

The new retrieval involves spectral measurements of atmospheric transmission from the Multi-Filter Rotating Shadowband Radiometer (MFRSR) at five wavelengths (415, 500, 615, 675, and $870 \mathrm{~nm}$ ) for finding areal-averaged surface albedo. To evaluate the spectral and seasonal features of the retrieved surface albedo, we compare our albedo retrievals with collocated and coincident satellite- and tower-based albedo measurements. Henceforth, "retrieved" albedo refers to albedos obtained from the MFRSR instrument alone. The MFRSR data were acquired at the well-established Southern Great Plains (SGP) and Table Mountain sites supported by the U.S. Department of Energy's (DOE's) Atmospheric Radiation Measurement (ARM) Program (http://www.arm.gov/) and National Oceanic and Atmospheric Administration (NOAA) (http://www.esrl.noaa.gov/), respectively. Previously, tower-based data collected at these sites have been used to evaluate satellite-derived shortwave broadband surface albedo for clear-sky days and selected seasonally dependent conditions with relatively uniform landscapes [21,22].

Our study aims to demonstrate the retrieval feasibility for days with fully overcast and non-overcast (defined as being either clear or partly cloudy) conditions, and landscapes with various degrees of heterogeneity. To this end, our efforts address three main questions: (1) How do the retrieved spectral surface albedo values compare to those obtained from independent satellite- and tower-based measurements? (2) Are albedos derived from overcast skies applicable to clear days? and (3) How sensitive is the difference between the retrieved and measured albedos to surface heterogeneity? The following sections outline our retrieval algorithm (Section 2), review general features of the retrieved and measured albedos (Section 3), describe the integrated datasets relevant to our study (Section 4), and discuss the performance of our retrieval (Section 5).

\section{Approach}

The concentration and size distribution of cloud droplets control $\tau$ and $r_{e}$ and therefore the relative amount of incoming solar radiation which is reflected, absorbed and transmitted by clouds. Numerical computations of the reflection, absorption and transmission for an overcast cloud layer are almost always based on a one-dimensional (1D) RT approximation [19,23] where the multiple scattering effects associated with surface albedo can be easily incorporated. Corresponding analytical solutions can be obtained for specific cases, including optically thick cloud layers. These solutions provide a general understanding of the impact of cloud/surface properties on atmospheric radiances; moreover, the solutions form the basis for estimating cloud properties operationally through measured irradiances. These solutions have several terms with coefficients related to cloud optical and microphysical properties. Obtaining these coefficients typically involves Mie-based parameterizations (the so-called semi-analytical solutions; [24]), or inferences based on data (the so-called semi-empirical solutions; [17,25]).

Let us consider one of these semi-empirical solutions obtained for optically thick $(\tau>5)$ and non-absorbing clouds [17] in fully overcast conditions. Coefficients of this solution, which represent the conservative scattering case, were found using multi-year measurements of atmospheric transmission at three ARM sites (tropical, continental, and Arctic regions), and complementary 
transmission-based $\tau$ retrievals. For spectral MFRSR data, the solution for $\tau$ is expressed by the equation

$$
\tau_{\lambda}=\frac{4}{3}\left(\frac{1}{t_{\lambda}}-1\right) /\left[\left(1-A_{\lambda}\right)\left(1-g_{\lambda}\right)\right]
$$

where $t_{\lambda}, A_{\lambda}$ and $g_{\lambda}$ are normalized atmospheric transmission, surface albedo and asymmetry factor for a given wavelength, respectively; the subscript " $\lambda$ " indicates the spectral dependence of these parameters. The normalized atmospheric transmission is defined as $t_{\lambda}=T_{\lambda} / \mu^{1.5}$, where $T_{\lambda}$ and $\mu$ are the measured atmospheric transmission and the cosine of solar zenith angle, respectively. Note that Kokhanovsky et al. [24] obtained a similar semi-analytical solution for the simplest case when an optically thick and non-absorbing overcast cloud layer is located above a "black" surface $\left(A_{\lambda}=0\right)$ and illustrated that this solution has the potential for retrieving $\tau$ and $r_{e}$ in the framework of conventional dual-channel methods.

Similar to Ricchiazzi et al. [16], we apply this framework for the simultaneous retrievals of $\tau_{\lambda}$ and $A_{\lambda}$. However, in contrast to Ricchiazzi et al. [16] who used detailed radiative transfer calculations, we apply the simple approach expressed by Equation (1). The latter can be re-written for the surface albedo estimation as

$$
A_{\lambda}=1-\frac{4}{3}\left(\frac{1}{t_{\lambda}}-1\right) /\left[\tau_{\lambda}\left(1-g_{\lambda}\right)\right]
$$

We emphasize that the replacement of the time-consuming RT calculations by the simple Equations (1) and (2) provides the opportunity for quick and routine retrievals of $\tau_{\lambda}$ and $A_{\lambda}$ from multi-spectral measurements of atmospheric transmission.

The two main steps of our approach are:

(1) Estimate cloud optical depth at $415 \mathrm{~nm}$ using Equation (1). This equation includes the measured normalized transmission $\left(t_{415}\right)$ and two input parameters $\left(A_{415}\right.$ and $\left.g_{415}\right)$. These two parameters can either be assumed or obtained from independent measurements. We assume that $A_{415}$ is small (0.03) and does not depend on surface type and solar zenith angle, and that $g_{415}$ is equal to its typical value (0.87) for liquid water clouds [26]. The assumption that $A_{415}$ is small (0.03) is generally a very good assumption for all surfaces except snow, ice, sand, and concrete [20].

(2) Estimate spectral surface albedo at other wavelengths using Equation (2). This equation includes the measured normalized transmission $\left(t_{\lambda}\right)$ and two cloud parameters $\left(\tau_{\lambda}\right.$ and $\left.g_{\lambda}\right)$ for a given wavelength. Here we assume that cloud optical depth depends only slightly on wavelength within the spectral range considered here (415-870 nm): $\tau_{\lambda}=\tau_{415} c_{\lambda}$. Values of the spectrally variable coefficient $c_{\lambda}$ are obtained from conventional tables [26]. This coefficient does not vary much from the value of one. We also assume that the asymmetry factor is spectrally independent $\left(g_{\lambda}=g_{415}\right)$ for all wavelengths. Note that the almost spectrally neutral behavior of the two major cloud parameters $\left(\tau_{\lambda}\right.$ and $\left.g_{\lambda}\right)$ in the considered spectral range (415 $\mathrm{nm}$ to $870 \mathrm{~nm}$ ) has been confirmed time and time again by many observational and 
theoretical studies $[18,19,26]$. The retrieved albedo does not depend on the assumed asymmetry factor $\left(g_{415}\right)$ and is not very sensitive to the assumed surface albedo $\left(A_{415}\right)$; see Appendix A.

The retrieval simplifications are motivated, to some extent, by the limited knowledge of cloud and atmospheric properties required for detailed RT calculations. Assumptions made for steps 1 and 2 implicitly assume that the spectral changes of observed atmospheric transmission are determined mostly by the spectral variations of the surface albedo. Whether this simplified approach works can be evaluated by comparing retrieved and measured surface albedos and considering important issues associated with surface inhomogeneity. Let us outline the general features of the measured and retrieved surface albedo and some expected challenges of the retrieval evaluation.

\section{Areal-Averaged and Point Surface Albedo}

Tower-based instruments mounted at several meters above the ground "see" only a relatively small area. For example, if a downward-looking instrument is mounted about $10 \mathrm{~m}$ above the surface, more than $90 \%$ of the upwelling radiation comes from an area only 60 meters in diameter below the instrument (Appendix B). Because of this very limited field of view the tower-based measurements represent "local" or "point" values of surface albedo. On the other hand, our retrieval estimates the surface albedo from the measured atmospheric transmission, which includes sunlight reflected by the ground and then "bounced" back to the surface by the cloud deck. The amount of "bounced" sunlight is proportional to the upwelling radiation at cloud base (Appendix B). Since overcast and optically thick clouds are frequently located above $0.5 \mathrm{~km}$ above the ground [27,28], irradiances reflected by the cloud back to the surface come from a wide surface area-much larger than the limited area seen by a tower-mounted sensor. Thus, our transmission-based retrievals represent "areal-averaged" values of surface albedo.

Theoretically, the measured local and retrieved values of surface albedo would be identical if both the measurements and retrievals of surface albedo were performed over an absolutely homogeneous surface. However, there is growing empirical evidence that for the majority of landscapes the surface albedo exhibits large variability over a wide range of spatial scales [12]. Therefore, a meaningful comparison of the local and areal-averaged values of surface albedo is typically obscured by challenges associated with surface inhomogeneity and spatial representativeness of point measurements for determining the areal-averages $[21,29]$. Weighted averages of point albedo data are commonly applied for approximating the areal-averaged surface albedo for landscapes with various degrees of heterogeneity [30].

Our simple retrieval relies on the application of 1D RT theory and, therefore it does not account for several important RT drivers, including changes of cloud optical properties at small spatial and temporal scales. To reduce the potential impact of these small-scale changes on our retrievals, daily-averaged values of the retrieved and measured surface albedo are considered because averaging suppresses random noise. Moreover, recognizing that the diurnal variability of surface albedo associated with solar zenith angle changes is more pronounced when the sun is low in the sky $(\mu<0.4)[4,31]$, we calculate the daily-averaged values of surface albedo only for larger solar zenith angles $(\mu>0.4)$. Finally, our retrieval does not explicitly account for the atmospheric aerosol located beneath a cloud layer, which can modify the transmission of a cloudy atmosphere and, thus, can change the difference 
between the local and areal-averaged values of surface albedo. Recently, Jäkel et al. [32] demonstrated that the anticipated aerosol impact on this difference is much smaller than the impact of surface heterogeneity for moderate aerosol loading (aerosol optical depth $<0.4$ ) and the spectral range (415-870 nm) considered here.

\section{Data Description}

We use data collected at two continental sites in United States: the ARM SGP Central Facility located in Oklahoma (https://www.arm.gov/sites/sgp/C) and the NOAA Table Mountain site located in Colorado (http://www.esrl.noaa.gov/gmd/grad/surfrad/tablemt.html). Hereafter, the terms "ARM site" and "NOAA site" will refer to these two well-established sites with suites of many instruments. Included in this collection of instruments are collocated ground-based MFRSRs and tower-based, downward-looking Multi-Filter Radiometers (MFRs; the MFR is the sensing head of an MFRSR) for measuring spectral atmospheric transmission and surface albedo, respectively. In addition to the spectral radiation measurements, the instrumentation includes broadband shortwave pyranometers. We use these measurements along with a standard approach [33] for identifying completely overcast conditions (although data from the broadband, silicon MFRSR channel can be used for the same purpose obviating the need for pyranometer measurements).

Recall that our method is designed to retrieve the areal-averaged surface albedo for cases when the sky is completely overcast (Section 2). We again emphasize that tower-based measurements of surface albedo are performed for both the overcast and non-overcast skies and thus represent diffuse and total albedos, respectively [22]. The diffuse (total) albedo is defined as the ratio between the total upward and diffuse (total) downward irradiances. In contrast to the diffuse albedo, the total albedo with the diffuse and direct-beam components depends substantially on the solar zenith angle (SZA) and this dependence is governed mainly by the direct-beam albedo [22]. The latter can be obtained from the diffuse and total albedos measured during "nearby" overcast and clear-sky conditions [4]. Here, we use tower-based measurements of the diffuse and total albedo for assessing the representativeness of the overcast values of surface albedo for non-overcast conditions, as explained below.

The ARM and NOAA sites have distinct visual appearances from the air and ground (Figures 1 and 2) mainly due to different surface types. The ARM site represents three major landscape classes: vegetated, partly vegetated and non-vegetated land cover with strong seasonal variability [34]. To sample this variability, the ARM site includes two downward-pointing MFRs mounted at $25 \mathrm{~m}$ and at $10 \mathrm{~m}$ above the ground on the 60 - and 10-m towers (Figure 1), respectively. Two upward-looking MFRSRs are deployed at the surface. The 60-m tower [35] is located within a managed field where a variety of crops are planted and harvested irregularly year to year according to a given farming plan. For example, wheat is planted occasionally in winter near the $60-\mathrm{m}$ tower [34]. In contrast, the 10-m tower is located in an unmanaged pasture where seasonal changes of surface albedo are quite consistent on annual time scales.

Compared to the ARM site (Figure 1), the NOAA site (Figure 2) has poorly vegetated "brown" sub-area surrounded by partly vegetated regions with "green" patches (Figure 2; bottom part). These patches define different types of vegetation, such as grass, bushes and trees. The 10-m tower with downward-looking MFR mounted at $8 \mathrm{~m}$ is located within the "brown" sub-area (Figure 2). 
Figure 1. Aerial image of the Southern Great Plains (SGP) site (left, taken from Google maps on 7 May 2014) and ground-based image of 60-m tower (right, from [35]). The aerial image (about $1 \times 1 \mathrm{~km}^{2}$ ) indicates the locations of the ground-based Multi-Filter Rotating Shadowband Radiometer (MFRSR) and the two towers (60-m and 10-m) with downward- and upward-looking Multi-Filter Radiometers (MFRs). Also, the image illustrates that these towers are located within sub-areas with different surface types.
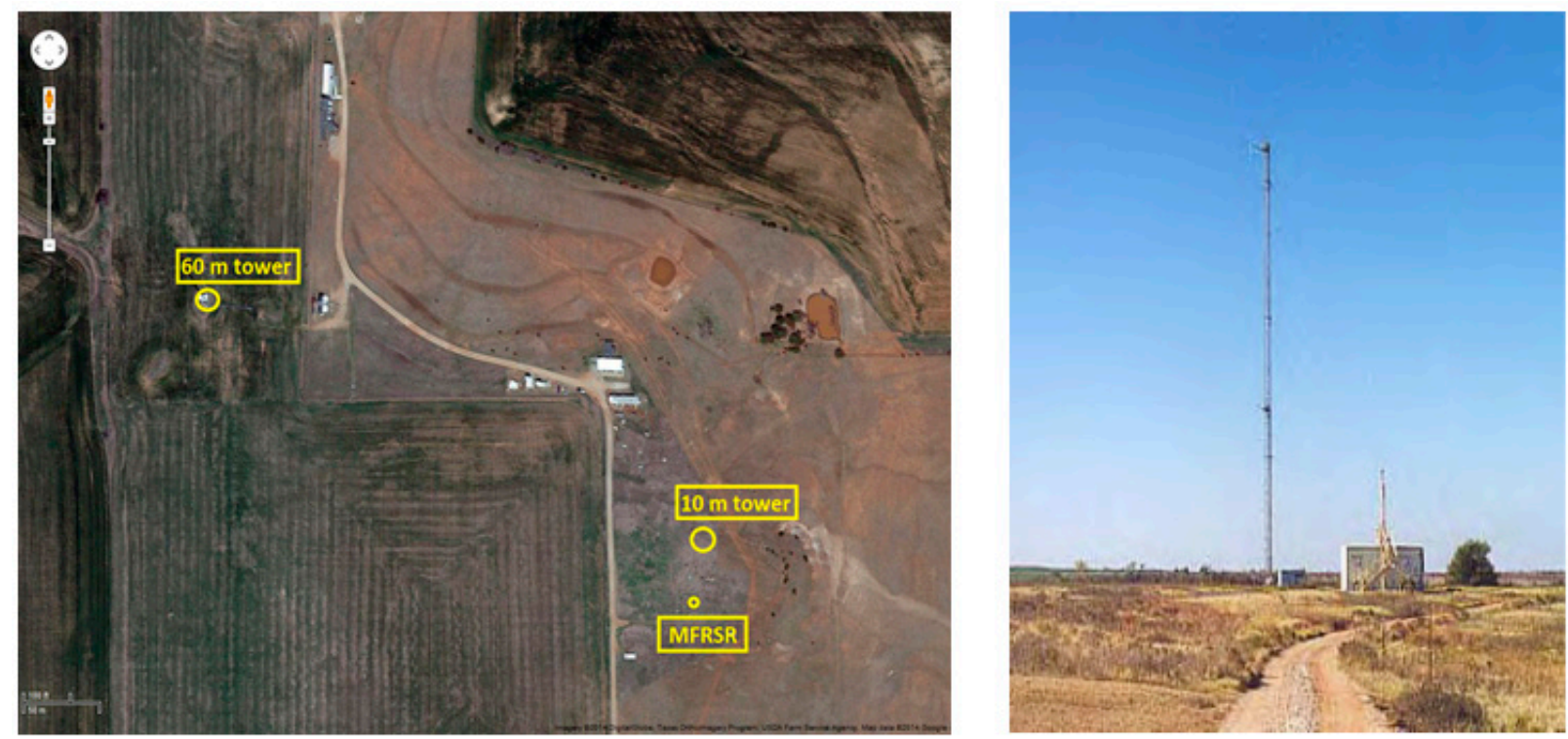

Figure 2. Aerial image of the National Oceanic and Atmospheric Administration (NOAA) site (left, taken from Google maps on 7 May 2014) and ground-based image of the 10-m tower (right, from http://www.esrl.noaa.gov/gmd/grad/surfrad/tablemt.html). The image (about $1 \times 1 \mathrm{~km}^{2}$ ) illustrates that this tower is surrounded by several sub-areas with different surface types, including "brown" soil and "green" vegetation.
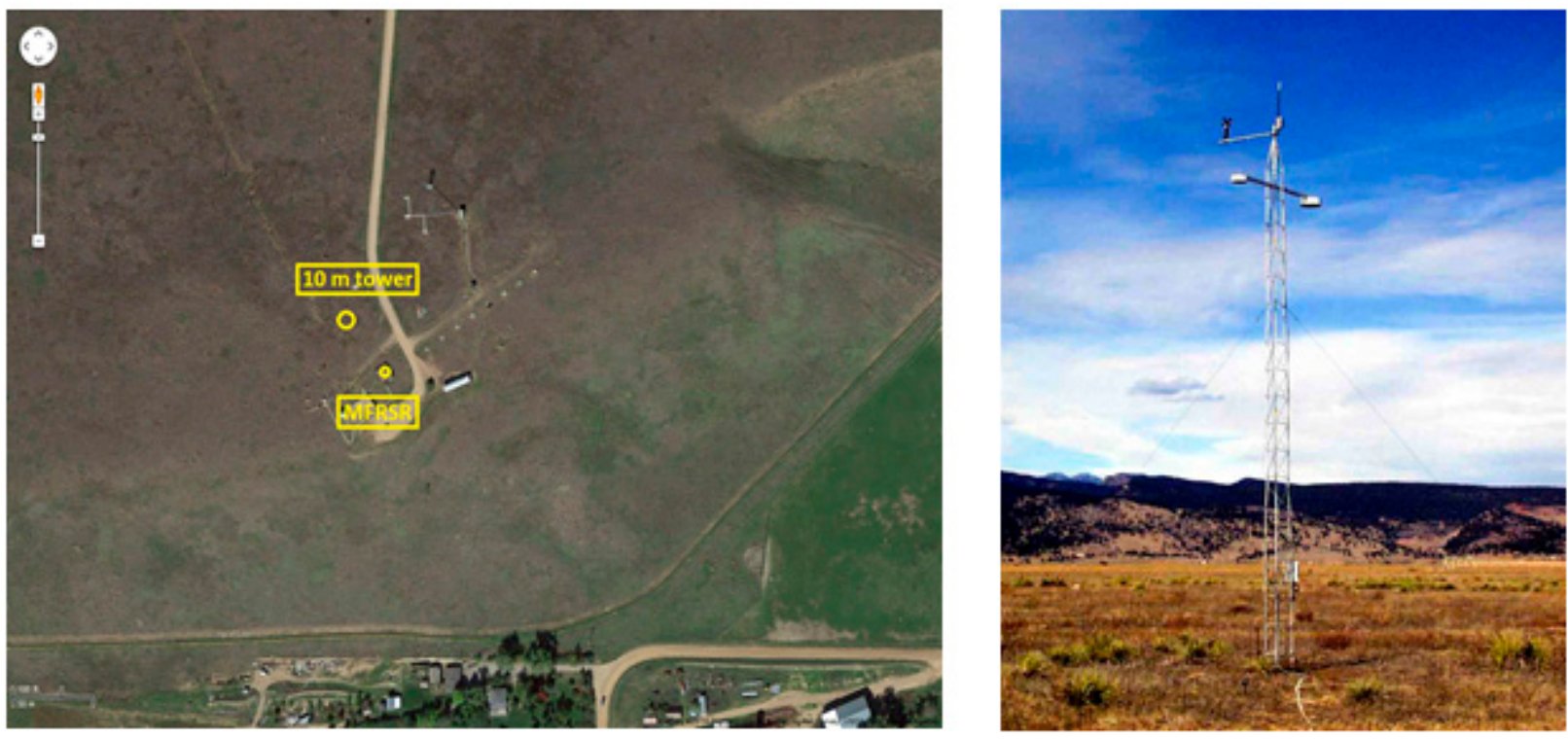

For our analysis, we consider the MFRSR and MFR data collected at five wavelengths $(415,500$, 615,675 and $870 \mathrm{~nm}$ ) during a fairly short interval at the NOAA site (April-May 2010) and a much 
longer period at the ARM site (2008-2013). The selection of these locations and periods is driven mainly by the wide diversity of surface types and the availability and quality of relevant data. Our analysis involves: (1) retrieving the areal-averaged surface albedo from the measured atmospheric transmission; and (2) comparing the retrieved and measured values of surface albedo. At the ARM site, we use the measured tower-based values for calculating the weighted average albedo $\left(A_{\lambda}^{a}\right)$

$$
A_{\lambda}^{a}=(1-f) A_{\lambda}^{10}+f A_{\lambda}^{25}
$$

where $A_{\lambda}^{10}$ and $A_{\lambda}^{25}$ are the "local" $10-\mathrm{m}$ and $25-\mathrm{m}$ values of tower-based surface albedo, and the fraction $f$ determines the relative contribution of these local values to the weighted average surface albedo. As a first approximation, we assume that $f=0.5$ and that it does not depend on time and wavelength; that is, we simply average the two values. Only samples with good quality local data $\left(A_{\lambda}^{10}\right.$ and $A_{\lambda}^{25}$ ) are used for calculating the average. Since the NOAA site has only one tower, a weighted average cannot be estimated from the tower data. Therefore, the tower-based NOAA albedos represent point values.

The ground-based measurements are accompanied by collocated satellite observations. In particular, we use the Moderate Resolution Imaging Spectroradiometer (MODIS) white-sky surface albedo data at four wavelengths $(470,560,670$ and $860 \mathrm{~nm})$. These data, with product designation MCD43B3 (https://lpdaac.usgs.gov/products/modis_products_table/mcd43b3; 1-km resolution), were downloaded from the MODIS Reprojection Tool Web Interface (MRTWeb) site (https://mrtweb.cr.usgs.gov/). White-sky albedos are obtained for nominal wavelengths of 470, 560, 670, and $860 \mathrm{~nm}$. We used these albedos for calculating the areal-averaged surface albedo in a $5 \times 5 \mathrm{~km}^{2}$ area surrounding the ARM and NOAA sites approximately centered over the site in question. These albedo values $\left(A_{\lambda}^{m}\right)$ are considered as a reference (not necessarily ground "truth") in our evaluation.

Only MODIS albedo values of the highest quality are used for this study. The quality information for each pixel is given in the MODIS product, MCD43B2, also downloaded from the MRTWeb site. The quality flags are discussed in https://pdaac.usgs.gov/products/modis_products_table/mcd43b2, under the heading of "layers", with variable name "BRDF_Albedo_Band_Quality". We only used so-called "best quality" data (quality flag equal to zero). Using the best quality data reduced the size of the original data sets, depending on MODIS band and location. For the NOAA site, only 10 points of band $3(470 \mathrm{~nm})$ data, out of a total of 175, were not of highest quality. Excluding these data made no significant difference in the analysis. For the SGP site, the number of excluded points depended on the season. For the winter season, defined as December, January, and February, about 35\% of the pixels were excluded (including points that were deleted by our own quality assurance scheme). For the other seasons the number of rejected points was much less. For spring (March, April, May), summer (June, July August), and fall (September, October, November) the reduction of points was $7 \%, 27 \%$, and 13\%, respectively. Exclusion of these points made a difference of at most 0.01 in derived MODIS albedos, with the largest changes occurring in winter; the changes during the other seasons were insignificant.

Given good quality data, we start with visual inspection of the temporal and spectral changes of the retrieved and measured/derived albedos (Figures 3-8). Such inspection is aimed to illustrate qualitative similarities and differences between albedos obtained from different platforms (e.g., similar seasonal trends and relative position of maximum values). We also include the corresponding quantitative comparisons (Tables 1 and 2) using calculated root mean square error (RMSE) values. Similar to an earlier study [21], we assume that a good agreement is achieved if the RMSE does not exceed 0.015 . 
Figure 3. Time series of the (a) tower-measured local and (b) MFRSR-retrieved areal-averaged surface albedo at the NOAA site during the two-month period (April-May 2010). Here time is day of year. Black, red, purple and green colors define the surface albedo values at four wavelengths $(415,500,673$ and $870 \mathrm{~nm})$. Also, the MODIS-derived surface albedo values at two wavelengths $(670$ and $860 \mathrm{~nm})$ are included (blue, green dots).

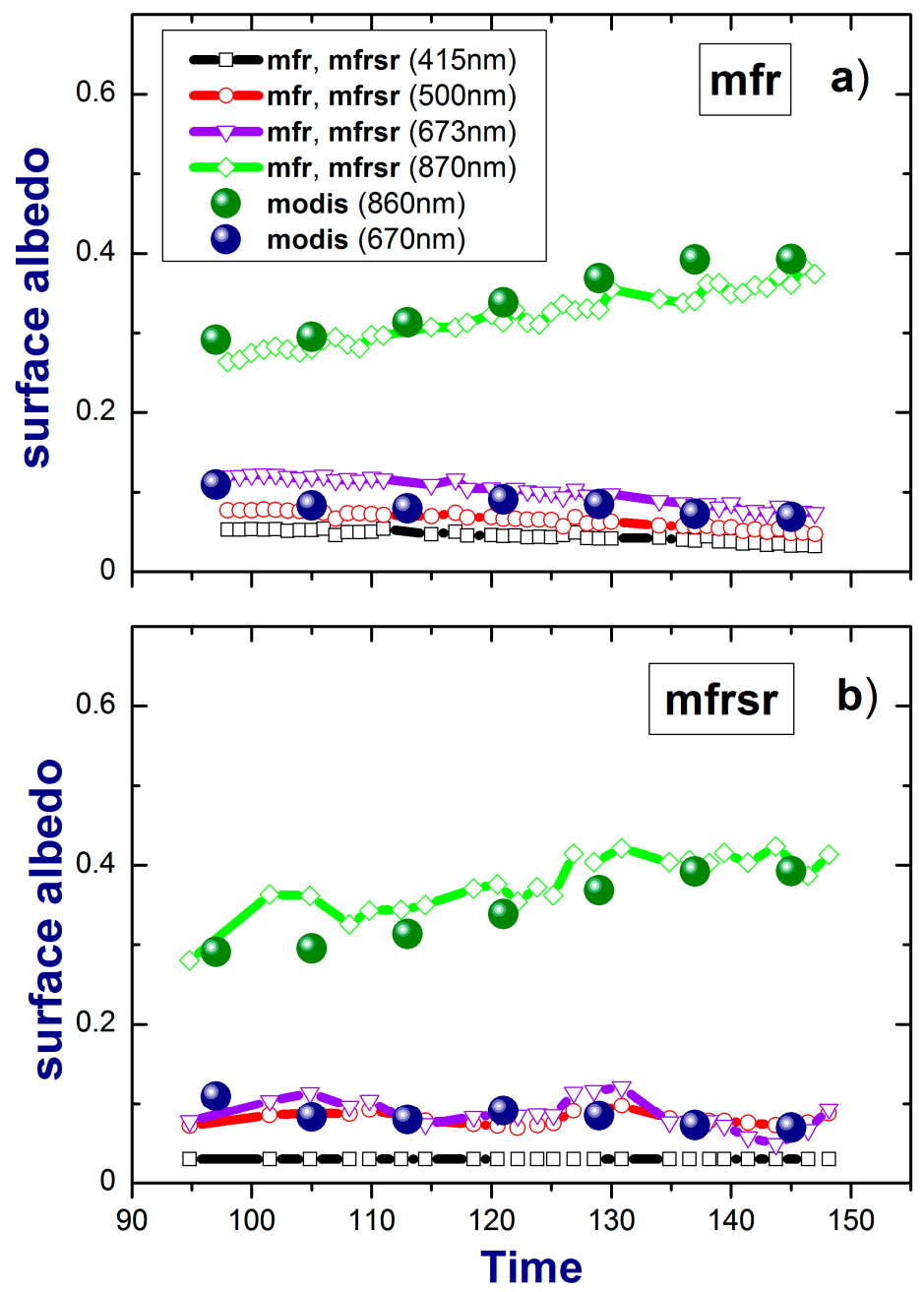

In line with this study [21], we calculate the RMSE values for comparing our retrieved areal-averaged surface albedo and albedos derived from satellites. The RMSE is defined as the root mean squared difference between the MODIS surface albedo and the technique in question. More explicitly, we find the difference between the MODIS albedo at these wavelengths $(500,615,673$, and $870 \mathrm{~nm}$ ) and the albedo of the instrument of interest. These differences are squared, averaged, and the square root is taken to find the RMSE. To calculate the RMSE, the MODIS surface albedo values have been interpolated/extrapolated to four of the five MFRSR/MFR wavelengths $(500,615,673,870 \mathrm{~nm})$ using linear interpolation/extrapolation. We do not extrapolate the MODIS data to $415 \mathrm{~nm}$ because the extrapolation "reach" from $470 \mathrm{~nm}$ (a $55 \mathrm{~nm}$ interval) is considered to be too extreme. On the other hand, we consider the extrapolation of MODIS data from $860 \mathrm{~nm}$ to $870 \mathrm{~nm}$ (a $10 \mathrm{~nm}$ interval) to be acceptable. Also, we calculate the corresponding RMSEs (MODIS surface albedo versus tower-based surface albedos) for estimating how well the measured "local" tower-based albedos represent albedos for the large $\left(5 \times 5 \mathrm{~km}^{2}\right)$ area encompassing the ARM and NOAA sites. 
Figure 4. Mean values ( \pm standard deviations) of the tower-measured local (green), MFRSR-retrieved areal-averaged (red) and MODIS-derived (blue) white-sky surface albedos as a function of wavelength. The mean local values represent overcast (a) and non-overcast (b) conditions that occurred during the two-month period of interest (Figure 3). The MODIS-derived albedos are plotted at the MODIS nominal wavelengths of 470, 560, 670 , and $860 \mathrm{~nm}$. For both figures, the MODIS-derived and MFRSR-retrieved albedos are the same.
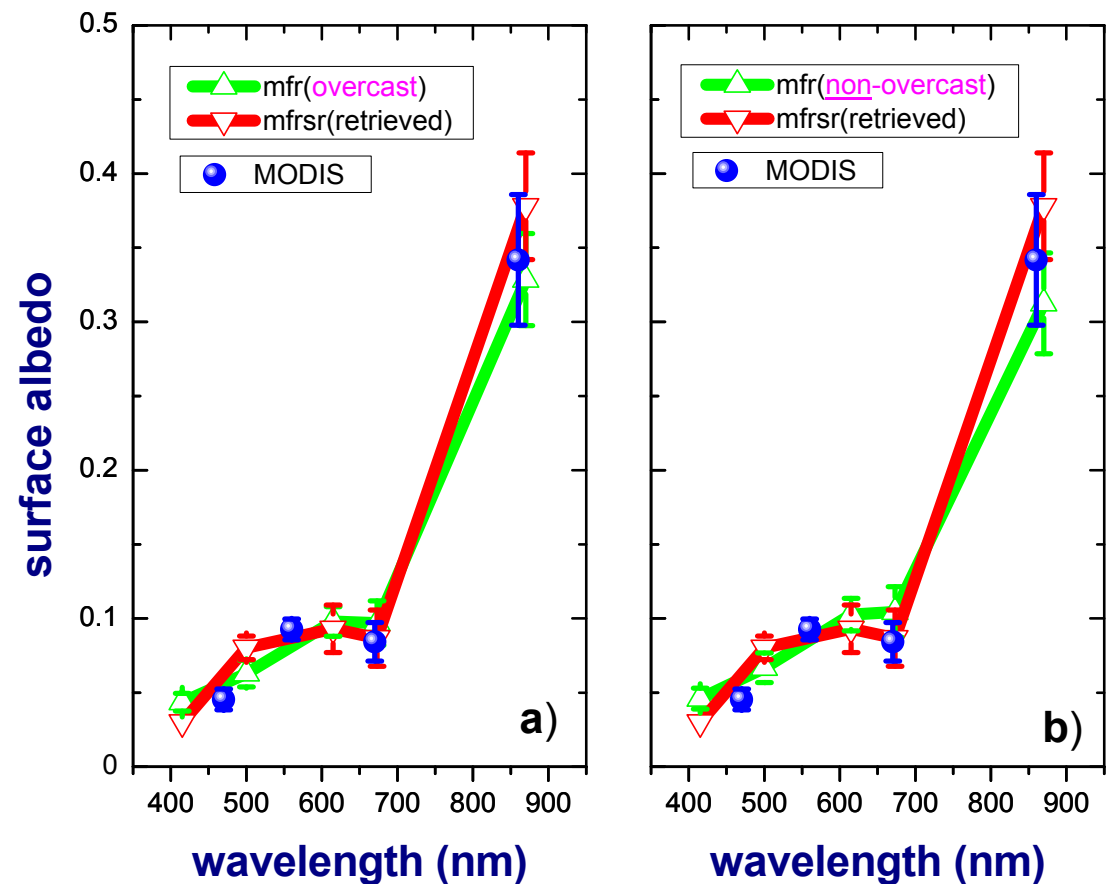

Three comparison-related comments should be made. First, the white-sky albedo represents the effects of diffuse radiation in the surface albedo derivation from MODIS data [22]. Thus, the white-sky albedo is directly comparable with the diffuse surface albedo measured/retrieved under overcast conditions. For non-overcast conditions, the MODIS-derived blue-sky albedo with the white-sky (for diffuse radiation) and black-sky (for direct beam) components is commonly assumed to be equivalent to the measured total surface albedo [22]. Second, the white-sky albedo is frequently assumed to be time-invariant during a day. In contrast to the white-sky albedo, the black-sky albedo has a well-known "U" shape with the smallest value occurring at local solar noon. As a result, the white-sky albedo overestimates (underestimates) the blue-sky albedo at local noon (near sunrise/sunset) (e.g., [22]; Figure 1). The magnitude of these overestimation/underestimations depends on relative contribution of the diffuse radiation to the total downward irradiance, and therefore on the atmospheric properties (e.g., aerosol loading). Third, the expected biases associated with these blue-sky albedo overestimation/underestimations will be partially canceled out during time integration over that part of the day when the solar zenith angle is relatively small. As a result, the difference between the daily-averaged white-sky and blue-sky albedos could be smaller than differences in the instantaneous values of white-sky and blue-sky albedos during a day (e.g., near local noon and/or near sunset/sunrise). Accordingly, we expect that the daily-averaged white-sky albedo could approximate quite well the daily-averaged total albedo measured under non-overcast conditions. 
Figure 5. Time series of the tower-measured 10-m (a) and 25-m (b) surface albedo at the ARM site, their weighted average (c), MODIS-derived (d) and MFRSR-retrieved areal-averaged surface albedo (e) for one-year period (2010). Red, blue and green colors define the surface albedo values $(\mathrm{a}-\mathrm{c}, \mathrm{e})$ at three MFR/MFRSR wavelengths $(500,673$ and $870 \mathrm{~nm}$ ). The MODIS data have been interpolated to these MFRSR wavelengths; (e) Solid lines (red, green, and blue) represent the smoothed versions of MFRSR-retrieved surface albedos at these wavelengths (500, 673 and $870 \mathrm{~nm}$ ) (boxcar averaging; 5 points). Appendix $\mathrm{C}$ includes related version of Figure 5 for other years and wavelengths.
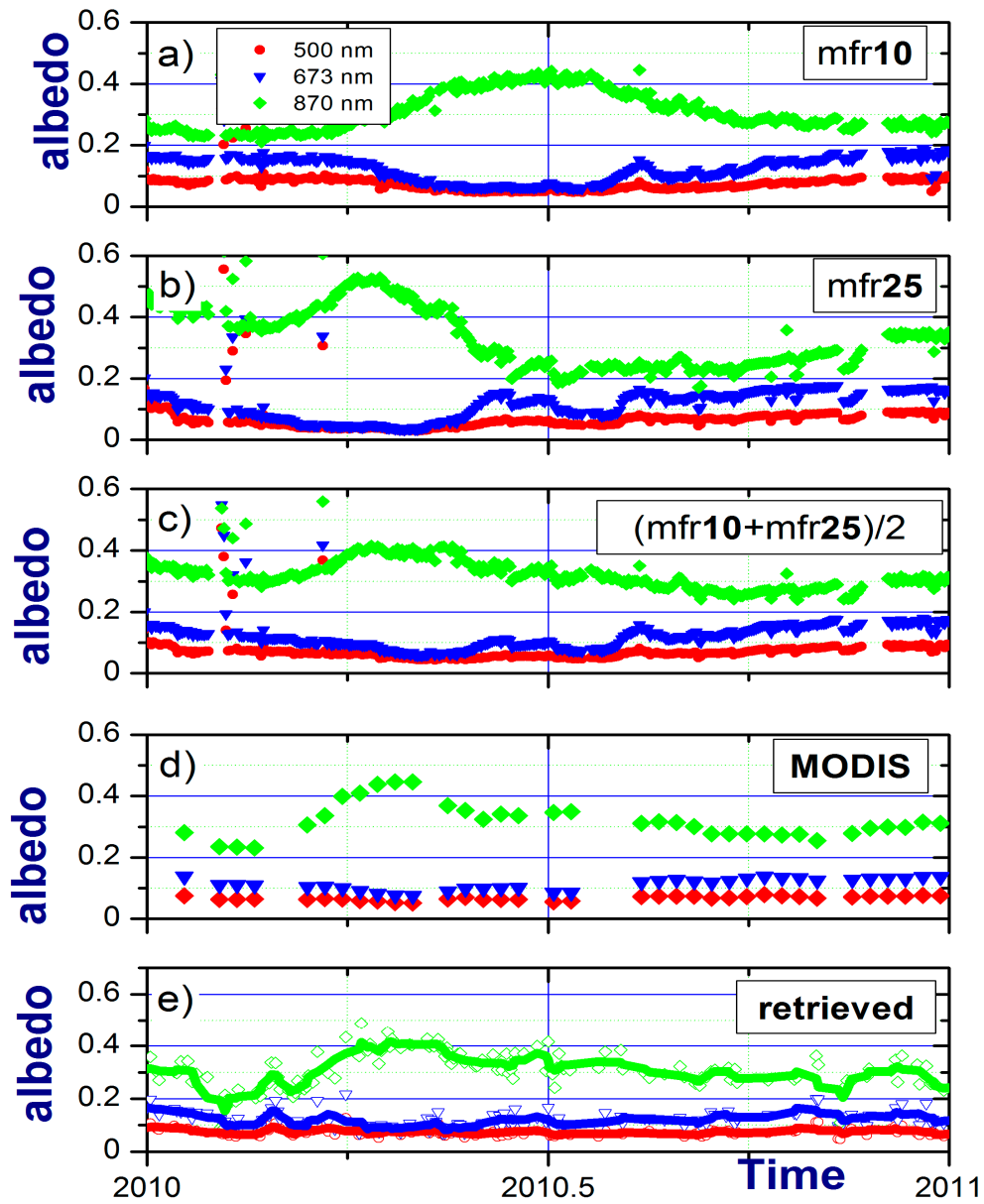

Figure 6. Time series of the MFRSR-retrieved areal-averaged surface albedo (magenta) and MODIS-derived albedo (blue) at three MFR/MFRSR wavelengths: $500 \mathrm{~nm}$ (a); $673 \mathrm{~nm}$ (b); and $870 \mathrm{~nm}$ (c) for one-year period (2010). In contrast to Figure 5, these time series are segregated by wavelength and focus on the comparison of the retrieved and MODIS-derived albedos.

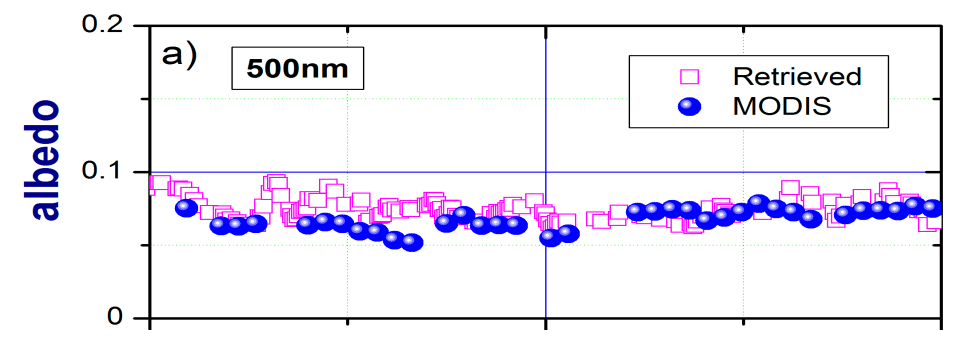


Figure 6. Cont.

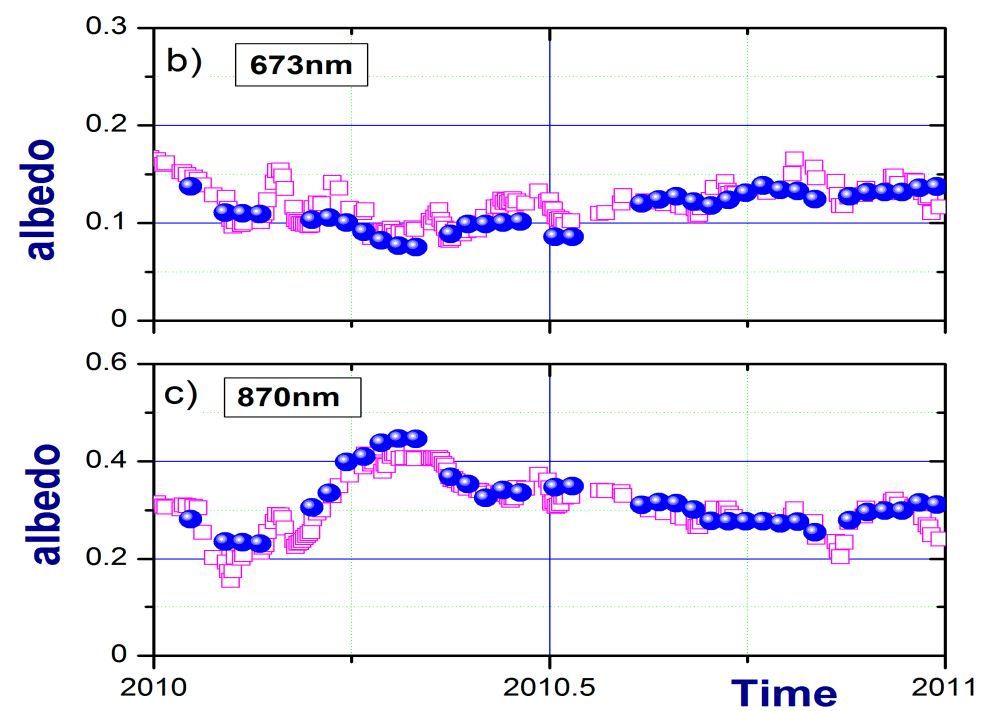

Figure 7. Spectral surface albedo values for overcast conditions during five-year period (2008-2013). Mean values ( \pm standard deviations) of the tower-measured 10-m (blue-dotted) and 25-m (magenta-dotted) albedo, their weighted average (solid-green), MODIS-derived (blue) and areal-averaged albedo (solid-red) as a function of wavelength for four seasons: winter (a); spring (b); summer (c) and fall (d).
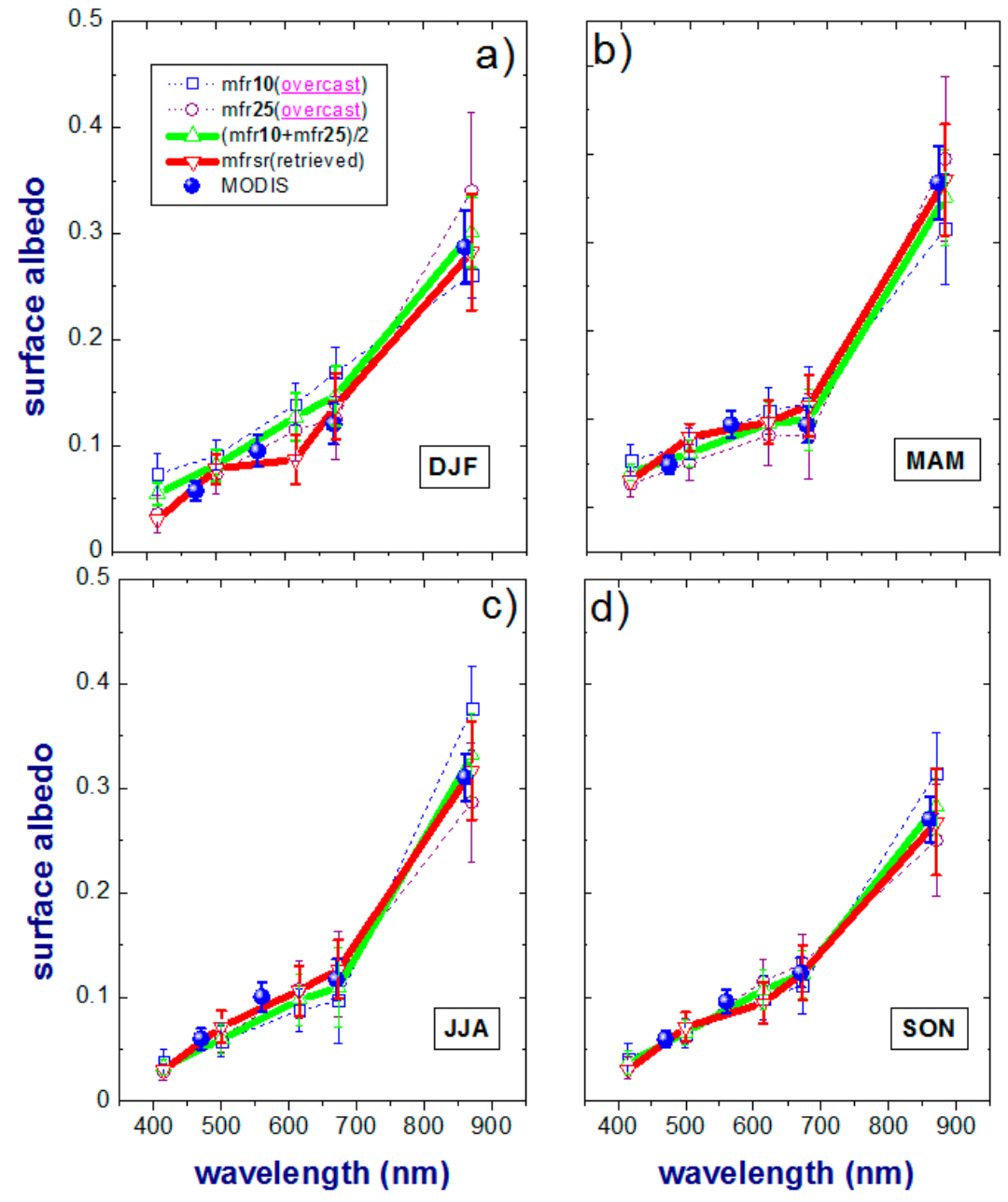
Figure 8. Spectral surface albedo values for non-overcast conditions during five-year period (2008-2013). Mean values ( \pm standard deviations) of the tower-measured 10-m (blue-dotted) and 25-m (magenta-dotted) albedo, their weighted average (solid-green), MODIS-derived (blue) and areal-averaged albedo (solid-red) as a function of wavelength for four seasons: winter (a); spring (b); summer (c) and fall (d).
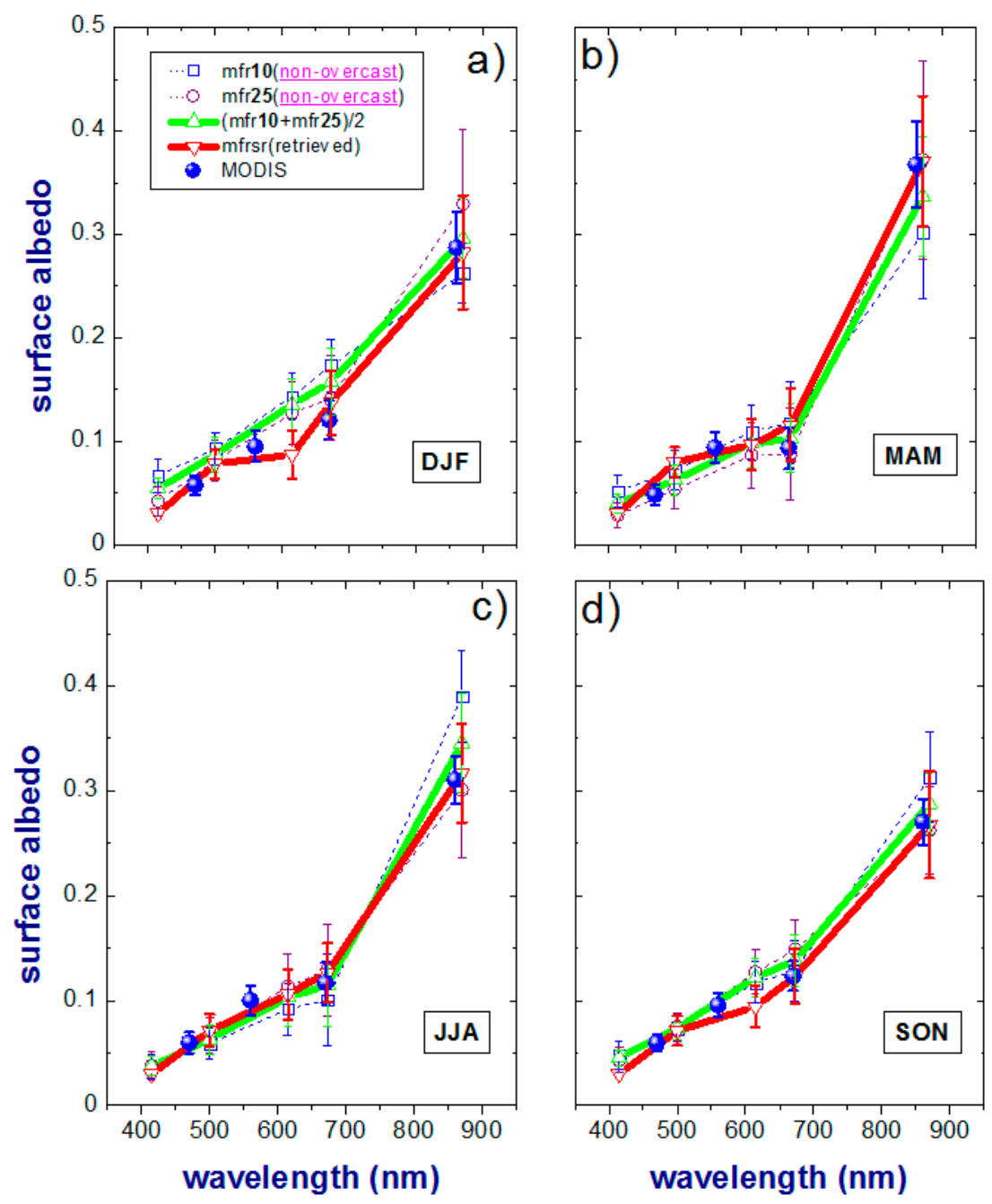

Table 1. Time-averaged albedos and the corresponding standard deviations (in parenthesis) derived from the indicated platforms for the NOAA site. For the tower data, both fully overcast and non-overcast conditions are shown. The MODIS data have been interpolated/extrapolated to the nominal MFRSR wavelengths. The root mean square error (RMSE) is also shown (bottom row) using the MODIS albedos as the reference. The two lowest RMSEs are indicated in bold.

\begin{tabular}{ccccc}
\hline Wavelength (nm) & MFRSR (Overcast) & MODIS (White Sky) & Tower (Overcast) & Tower (Non-Overcast) \\
\hline 415 & $0.030(0.0)$ & - & $0.044(0.006)$ & $0.046(0.007)$ \\
\hline 500 & $0.080(0.008)$ & $0.061(0.006)$ & $0.063(0.009)$ & $0.066(0.010)$ \\
\hline 615 & $0.093(0.016)$ & $0.088(0.008)$ & $0.098(0.010)$ & $0.103(0.011)$ \\
\hline 673 & $0.087(0.019)$ & $0.088(0.012)$ & $0.098(0.015)$ & $0.104(0.017)$ \\
\hline 870 & $0.378(0.036)$ & $0.355(0.043)$ & $0.329(0.031)$ & $0.312(0.034)$ \\
\hline RMSE & $\mathbf{0 . 0 1 5}$ & - & $\mathbf{0 . 0 1 5}$ & 0.024 \\
\hline
\end{tabular}


Table 2. Time-averaged albedos and the corresponding standard deviations (in parenthesis) derived from the indicated platforms for the ARM site, segregated by season: winter (a), spring (b), summer (c), fall (d). For the tower data, both fully overcast and non-overcast conditions are shown. The MODIS data have been interpolated/extrapolated to the nominal MFRSR wavelengths. The root mean square error (RMSE) is also shown (bottom row) using the MODIS albedos as the reference. The two lowest RMSE are indicated in bold.

(a)

\begin{tabular}{ccccccccc}
\hline Wave Length (nm) & MFRSR (Retrieved) & MODIS (Derived) & Tower (Weighted-Average) & \multicolumn{2}{c}{ Tower (10-m) } & Tower (25-m) \\
\hline & Overcast & White-Sky & Overcast & Non-Overcast & Overcast & Non-Overcast & Overcast & Non-Overcast \\
\hline 415 & $0.030(0.0)$ & - & $0.054(0.011)$ & $0.054(0.010)$ & $0.073(0.020)$ & $0.066(0.016)$ & $0.035(0.018)$ & $0.042(0.014)$ \\
\hline 500 & $0.078(0.014)$ & $0.070(0.009)$ & $0.082(0.015)$ & $0.087(0.017)$ & $0.095(0.014)$ & $0.093(0.016)$ & $0.073(0.019)$ & $0.081(0.020)$ \\
\hline 615 & $0.087(0.023)$ & $0.108(0.015)$ & $0.127(0.023)$ & $0.135(0.025)$ & $0.139(0.020)$ & $0.143(0.022)$ & $0.115(0.029)$ & $0.127(0.030)$ \\
\hline 673 & $0.137(0.031)$ & $0.113(0.019)$ & $0.147(0.028)$ & $0.157(0.032)$ & $0.169(0.023)$ & $0.173(0.026)$ & $0.125(0.039)$ & $0.141(0.041)$ \\
\hline 870 & $0.283(0.055)$ & $0.296(0.034)$ & $0.301(0.033)$ & $0.296(0.039)$ & $0.261(0.023)$ & $0.263(0.029)$ & $0.340(0.074)$ & $0.329(0.072)$ \\
\hline RMSE & $\mathbf{0 . 0 0 9}$ & - & $\mathbf{0 . 0 1 0}$ & 0.014 & 0.019 & 0.020 & 0.012 & 0.012 \\
\hline
\end{tabular}

(b)

\begin{tabular}{ccccccccc}
\hline Wave Length (nm) & MFRSR (Retrieved) & MODIS (Derived) & Tower (Weighted-Average) & Tower (10-m) & Tower (25-m) \\
\hline & Overcast & White-Sky & Overcast & Non-Overcast & Overcast & Non-Overcast & Overcast & Non-Overcast \\
\hline 415 & $0.030(0.0)$ & - & $0.040(0.009)$ & $0.040(0.009)$ & $0.053(0.018)$ & $0.052(0.016)$ & $0.026(0.014)$ & $0.028(0.012)$ \\
\hline 500 & $0.079(0.015)$ & $0.063(0.010)$ & $0.061(0.015)$ & $0.062(0.015)$ & $0.072(0.018)$ & $0.071(0.019)$ & $0.051(0.020)$ & $0.053(0.019)$ \\
\hline 615 & $0.097(0.025)$ & $0.093(0.015)$ & $0.095(0.023)$ & $0.098(0.023)$ & $0.109(0.026)$ & $0.109(0.026)$ & $0.081(0.034)$ & $0.086(0.032)$ \\
\hline 673 & $0.115(0.035)$ & $0.098(0.020)$ & $0.099(0.035)$ & $0.103(0.033)$ & $0.118(0.041)$ & $0.118(0.040)$ & $0.080(0.048)$ & $0.088(0.044)$ \\
\hline 870 & $0.371(0.063)$ & $0.381(0.042)$ & $0.351(0.054)$ & $0.337(0.058)$ & $0.315(0.063)$ & $0.302(0.064)$ & $0.394(0.093)$ & $0.372(0.096)$ \\
\hline RMSE & $\mathbf{0 . 0 0 6}$ & & 0.008 & 0.011 & 0.018 & 0.021 & 0.007 & $\mathbf{0 . 0 0 5}$ \\
\hline
\end{tabular}

(c)

\begin{tabular}{ccccccccc}
\hline Wave Length (nm) & MFRSR (Retrieved) & MODIS (Derived) & Tower (Weighted-Average) & \multicolumn{2}{c}{ Tower (10-m) } & \multicolumn{2}{c}{ Tower (25-m) } \\
\hline & Overcast & White-Sky & Overcast & Non-Overcast & Overcast & Non-Overcast & Overcast & Non-Overcast \\
\hline 415 & $0.030(0.0)$ & - & $0.033(0.007)$ & $0.037(0.009)$ & $0.037(0.012)$ & $0.037(0.011)$ & $0.028(0.008)$ & $0.038(0.014)$ \\
\hline 500 & $0.072(0.015)$ & $0.073(0.010)$ & $0.059(0.014)$ & $0.063(0.014)$ & $0.057(0.015)$ & $0.059(0.015)$ & $0.062(0.014)$ & $0.067(0.017)$ \\
\hline 615 & $0.106(0.024)$ & $0.109(0.014)$ & $0.097(0.024)$ & $0.103(0.027)$ & $0.087(0.021)$ & $0.092(0.025)$ & $0.107(0.028)$ & $0.114(0.031)$ \\
\hline 673 & $0.127(0.028)$ & $0.120(0.019)$ & $0.109(0.038)$ & $0.115(0.040)$ & $0.096(0.041)$ & $0.101(0.044)$ & $0.122(0.041)$ & $0.129(0.044)$ \\
\hline 870 & $0.317(0.047)$ & $0.321(0.023)$ & $0.331(0.040)$ & $0.345(0.047)$ & $0.376(0.040)$ & $0.390(0.044)$ & $0.287(0.057)$ & $0.301(0.064)$ \\
\hline RMSE & $\mathbf{0 . 0 0 4}$ & & $\mathbf{0 . 0 1 2}$ & 0.014 & 0.033 & 0.038 & 0.018 & $\mathbf{0 . 0 1 2}$ \\
\hline
\end{tabular}

(d)

\begin{tabular}{ccccccccc}
\hline Wave Length (nm) & MFRSR (Retrieved) & MODIS (Derived) & Tower (Weighted-Average) & \multicolumn{2}{c}{ Tower (10-m) } & Tower (25-m) \\
\hline & Overcast & White-Sky & Overcast & Non-Overcast & Overcast & Non-Overcast & Overcast & Non-Overcast \\
\hline 415 & $0.030(0.0)$ & - & $0.037(0.011)$ & $0.045(0.008)$ & $0.041(0.015)$ & $0.048(0.013)$ & $0.032(0.011)$ & $0.043(0.012)$ \\
\hline 500 & $0.071(0.014)$ & $0.072(0.008)$ & $0.066(0.012)$ & $0.074(0.011)$ & $0.064(0.013)$ & $0.073(0.012)$ & $0.068(0.012)$ & $0.075(0.013)$ \\
\hline 615 & $0.094(0.020)$ & $0.109(0.011)$ & $0.107(0.019)$ & $0.122(0.018)$ & $0.099(0.021)$ & $0.117(0.020)$ & $0.115(0.022)$ & $0.127(0.021)$ \\
\hline 673 & $0.123(0.026)$ & $0.126(0.014)$ & $0.122(0.023)$ & $0.138(0.025)$ & $0.111(0.027)$ & $0.128(0.029)$ & $0.133(0.027)$ & $0.149(0.028)$ \\
\hline 870 & $0.268(0.051)$ & $0.278(0.022)$ & $0.282(0.027)$ & $0.287(0.029)$ & $0.315(0.039)$ & $0.313(0.043)$ & $0.250(0.053)$ & $0.262(0.041)$ \\
\hline RMSE & $\mathbf{0 . 0 0 9}$ & & $\mathbf{0 . 0 0 4}$ & 0.010 & 0.021 & 0.018 & 0.016 & 0.017 \\
\hline
\end{tabular}


In an earlier study, Jin et al. [21] used 30-m spatial resolution Landsat Enhanced Thematic Mapper Plus (ETM+) images to show that the degree of surface heterogeneity (at a $1 \mathrm{~km}^{2}$ spatial scale) over the ARM and NOAA sites is generally smaller during the growing seasons (e.g., spring and summer) compared to the non-growing seasons (e.g., winter). Thus, we expect that agreement between the surface albedo values calculated from 1-km MODIS data and those retrieved by our simple approaches - tower-based and MFRSR-based-would be better for the growing seasons as well. Moreover, it is increasingly apparent that the spectral and spatial features for many regions are almost temporally invariant within a relatively short (1-4 weeks) period, and this weak temporal variability forms the basis for improved and simultaneous retrievals of aerosol and surface properties [36]. Therefore, we expect that our retrievals of "overcast" surface albedo would be representative for non-overcast days, as long as these days are not separated too far in time from the overcast days. We further discuss these two expectations related to seasonally varying surface heterogeneity and the representativeness of overcast retrievals in the next section.

\section{Results}

We start with the time series of the daily-averaged surface albedo measured at the NOAA site (Figure 3) during spring (April-May 2010). The "local" albedo values from the three wavelengths $(415,500$, and $673 \mathrm{~nm})$ of the tower MFR measurements are largest in the beginning of this period and then decrease slightly (Figure 3a). In contrast, the 870-nm surface albedo increases substantially (Figure 3a) during this period.

It is well-known that bare soil tends to have a larger albedo than green surfaces for wavelengths less than $700 \mathrm{~nm}$, but above $700 \mathrm{~nm}$, green surfaces have a larger albedo [3,20,34]. Therefore, the opposite trends for the surface albedo measured at the visible $(673 \mathrm{~nm})$ and near-infrared $(870 \mathrm{~nm})$ wavelengths (Figure 3a) can be explained by seasonal evolution of nearby vegetation seen by the $8-\mathrm{m}$ downward-looking MFR. That is, as increasing amounts of greening and growing vegetation cover bare ground surfaces (more green and less brown exposed to the downwelling irradiance), the albedo for wavelengths less than $700 \mathrm{~nm}$ decreases, while the albedo above $700 \mathrm{~nm}$ increases. The corresponding MODIS surface albedos at two wavelengths $(670$ and $860 \mathrm{~nm}$ ) also exhibit similar trends. Our retrieved areal-averaged surface albedo from the MFRSR data shows a weak day-to-day variability at $673 \mathrm{~nm}$ wavelength and an increasing trend at $870 \mathrm{~nm}$ wavelength (Figure $3 \mathrm{~b}$ ) in the same fashion as the MODIS surface albedo.

On average, the retrieved surface albedo captures the spectral changes of MODIS surface albedo reasonably well (Figure 3b; Table 1). The identical (0.015) RMSE values obtained for the retrieved areal-averaged MFRSR-based and measured point (tower) surface albedo under overcast conditions suggest that the degree of surface heterogeneity is quite small for the NOAA site during the period considered here (April-May 2010). This finding is in harmony with the previous results obtained for the growing seasons [21]. Even the RMSE values of 0.015 obtained for the spectral surface albedo for April-May 2010 are comparable with the value of 0.018 obtained earlier by other investigators for the $1 \times 1 \mathrm{~km}^{2}$ shortwave broadband surface albedo at this NOAA site during the April-September 2001 growing season [21]. 
Although the time series of the measured daily-averaged local (tower) surface albedo represents both overcast and non-overcast days (Figure 3a), distinct ups and downs in the time series-perhaps correlated with overcast versus non-overcast days-are not evident. This smoothness suggests that over several days or even weeks, overcast and non-overcast days have quite similar daily-averaged values, provided the overcast and non-overcast days are not separated by long periods of time. In other words, the daily-averaged overcast values are fairly representative for temporally "nearby" non-overcast days for both local and areal-averaged values.

This is clearly seen by comparing Figure $4 a-b$; each Figure shows the spectral variation of albedos at the NOAA site (where the albedos have been averaged over the two month period). Figure 4a shows results based on fully overcast days for both tower MFR-based measurements and MFRSR-based retrievals. Figure $4 b$ is based on the MFRSR-based retrievals for overcast days while the tower MFRbased averages are from non-overcast days. There is scarcely any difference between these two graphs. This finding is consistent with the generally accepted assumption about almost temporally invariant surface properties within a relatively short period [36], and suggests that albedos derived from our retrieval can be successfully extended to days that are not fully overcast by interpolating between days when retrievals are possible.

Let us examine the longer time series of the surface albedo measured at the ARM site (Figures 5 and 6). The seasonal changes of surface albedo are well-defined and attributed mostly to the corresponding seasonal variations of vegetation described thoroughly by McFarlane et al. [34]. As expected, the contribution of snow-covered areas to the measured surface albedo is occasionally large during the winter, and this contribution is responsible for infrequent outliers characterized by large values of the measured surface albedo (Figure 5a,b). Since the 10- and 25-m downward-looking MFRs see different sub-areas, a noticeable difference between $A_{\lambda}^{10}$ and $A_{\lambda}^{25}$ occurs quite often. For example, $A_{870}^{10}$ exceeds $A_{870}^{25}$ by about a factor of two for the summer of 2010 (Figure 5a,b; time $=2010.5$ ).

The average surface albedo $\left(A_{870}^{a}\right)$ derived from the tower measurements exhibits well-defined seasonal changes (Figure 5c) similar to its local components (Figure 5a,b). However, the range of $A_{870}^{a}$ variations is much smaller compared to the corresponding ranges of local values for a given period of interest (Figure 5c versus Figure 5a,b). For example, we consider the year 2010 again: the range (maximum minus minimum values) is about 0.3 and 0.2 for the local $A_{870}^{25}$ (Figure $5 \mathrm{~b}$ ) and the weighted average $A_{870}^{a}$ (Figure 5c) albedo, respectively. In addition to the substantial range reduction, the averaging of the two tower albedos can alter noticeably the pattern of seasonal and sub-seasonal changes, such as shifting peak positions of the surface albedo within a given period of interest (Figure 5c versus Figure 5a,b): peaks are observed during summer (around time $=2010.5$ ) and spring (near time $=2010.3$ ) for $A_{870}^{10}$ (Figure 5a) and weighted average $A_{870}^{a}$ (Figure 5c) albedo, respectively.

There are visual similarities between time series of the weighted average $A_{\lambda}^{a}$ (Figure 5c), MODIS-derived $A_{\lambda}^{m}$ (Figure 5d), and the retrieved areal-averaged $A_{\lambda}^{r}$ (Figure 5e) values. These similarities include comparable ranges and similar seasonal patterns during several periods of interest. To illustrate, we compare their seasonal patterns for year 2010: $A_{870}^{a}, A_{870}^{m}$ and $A_{870}^{r}$ reach the maximum values during spring (near time $=2010.3$ ), and then all exhibit comparable decreasing trends until the summer (around time $=2010.7$ ). Although a visual inspection of the temporal changes demonstrates a reasonable resemblance of the retrieved $A_{\lambda}^{r}$ and MODIS-derived $A_{\lambda}^{m}$ spectral values (Figure 6), we follow with a more quantitative comparison. For this comparison we must remove 
snow-contaminated points from the tower time series. These points are associated with large values of measured surface albedo (Figure 5a,b). We remove all points where the measured surface albedo at $415 \mathrm{~nm}$ wavelength exceeds 0.1 . These points occur only in winter and are likely associated with snow-related events, such as an either fully or partly snow covered surface seen by the tower-based instruments.

Our quantitative analysis is embodied in Figures 4, 7 and 8, which show the spectral behavior of the surface albedos, where the albedos at each wavelength have been averaged over time. First, considering the NOAA site (Figure 4), there is quite good qualitative agreement between our derived albedos, the albedos from the tower, and the albedos obtained from satellite data (Note that in Figure 4, the MODIS albedos are plotted at their nominal wavelengths). For the ARM site, the albedos are seasonally segregated with seasons defined as: winter (December-January-February; DJF), spring (March-April-May; MAM), summer (June-July-August; JJA) and fall (September-October-November; $\mathrm{SON}$ ). Reasonable qualitative agreement between all techniques is also apparent. The only instance where the agreement is compromised occurs in the winter season for a wavelength of $615 \mathrm{~nm}$ (Figure 7a). Here, the significant difference between $A_{\lambda}^{a}$ and $A_{\lambda}^{r}$ at $615 \mathrm{~nm}$ wavelength could be attributed to nearby sub-areas with "brown" dead vegetation [34] unseen by the tower-based instruments.

In contrast to this singular point, the retrieved $A_{\lambda}^{r}$, weighted average $A_{\lambda}^{a}$ and MODIS-derived $A_{\lambda}^{m}$ surface albedo exhibit very consistent spectral variation (Figure 7a). As a result, the corresponding RMSEs (0.009 and 0.010) are comparable as well (Table 2a). For the spring (MAM), summer (JJA), and fall (SON) with lower degrees of surface heterogeneity, the retrieved surface albedo $A_{\lambda}^{r}$ is a good approximation for the corresponding weighted average $A_{\lambda}^{a}$ (Figure $7 \mathrm{~b}-\mathrm{d}$; Table $2 \mathrm{~b}-\mathrm{d}$ ). Moreover, the retrieved albedo $A_{\lambda}^{r}$ matches the observational MODIS reference albedos $A_{\lambda}^{m}$ very well at four wavelengths (500, 615, 675 and $870 \mathrm{~nm}$ ) (Figure 7b-d): the resultant RMSE does not exceed 0.009 for all four seasons (Table $2 \mathrm{a}-\mathrm{d}$ ). We emphasize that the corresponding RMSE calculated for the 10-m surface albedo $A_{\lambda}^{10}$ can be considerably larger (up to 0.033 ) than that calculated for the retrieved areal-averaged albedo $A_{\lambda}^{r}$ (Table $2 \mathrm{~b}-\mathrm{d}$ ), suggesting that the $10-\mathrm{m}$ local surface albedo is not representative of an areal-averaged albedo. With only a few exceptions, the good agreement between the mean values of $A_{\lambda}^{a}$ and $A_{\lambda}^{r}$ is even evinced for non-overcast (Figure 8) conditions. The observed resemblance (overcast versus non-overcast results), obtained at the NOAA (Figure 4; Table 1) and ARM (Figures 7 and 8; Table 2) sites, confirms our expectation that the daily-averaged overcast retrievals of the areal-averaged surface albedo can be representative of non-overcast days.

\section{Summary}

We introduce a simple approach for retrieving the areal-averaged surface albedo from atmospheric transmission alone, measured at the surface under completely overcast conditions. The development of our approach with operational possibilities is motivated by earlier successful attempts [16] that used the conventional concept of dual-channel measurements and detailed radiative transfer (RT) calculations. In contrast to the previous studies that relied on time-consuming numerical RT simulations, our approach uses the semi-empirical equation [17], which analytically links the optical properties of an overcast cloud layer and the surface albedo with atmospheric transmission. Such a simple approach 
provides an opportunity for operational retrievals of areal-averaged surface albedo and cloud properties when multi-spectral measurements of the atmospheric transmission are available.

We retrieve the areal-averaged surface albedo using the atmospheric transmission measured at five wavelengths $(415,500,615,673$ and $870 \mathrm{~nm})$ by ground-based Multi-Filter Rotating Shadowband Radiometers (MFRSR) deployed at two continental sites in the United States, the ARM Southern Great Plains (SGP) site and the NOAA Table Mountain site. These sites, supported by ARM (http://www.arm.gov/) and NOAA (http://www.esrl.noaa.gov/), include towers for measuring surface albedo at five MFRSR wavelengths. The ground- and tower-based measurements of surface albedo are compared with corresponding Moderate Resolution Imaging Spectroradiometer (MODIS) satellite measurements. For our evaluation, we use $5 \times 5 \mathrm{~km}^{2}$ MODIS-derived white-sky surface albedo values at four nominal wavelengths $(470,560,670$ and $860 \mathrm{~nm})$. These MODIS values are interpolated/extrapolated to the four MFRSR wavelengths $(500,615,673,870 \mathrm{~nm})$ and are considered as reference values. We calculate the root mean square error (RMSE), which is defined as the root mean squared difference between the MODIS surface albedo and the retrieved/measured surface albedo. The NOAA and ARM integrated datasets with the ground-based and MODIS components cover short (April-May 2010) and long (2008-2013) periods, respectively.

At the NOAA site with its single tower $(10-\mathrm{m})$, both the MFRSR-based retrieved areal-averaged albedo and the tower-based measured albedo resemble, on average, the temporal trends and the spectral behavior of the MODIS-derived surface albedo reasonably well. The corresponding RMSEs between the MODIS albedos and the retrieved and measured albedos are identical (0.015), and comparable with that obtained previously for the $1 \times 1 \mathrm{~km}^{2}$ shortwave broadband surface albedo during the growing seasons [21]. At the ARM site with its two towers (60-m and 10-m), similarly good agreement is obtained for the MFRSR-based retrieved areal-averaged surface albedo values (RMSE $\leq 0.009)$ and tower-based weighted averages (RMSE $\leq 0.012)$. The fact that the retrieved albedos compare favorably with both the satellite and tower-averaged albedos suggests that the retrieved albedos are indeed representative of area-wide albedos. For surface albedos measured at the 10-m tower, the corresponding seasonally-dependent RMSE can be very large (up to 0.033), suggesting that albedos measured under the 10-m tower may not be representative of albedos of a larger area.

At the NOAA and ARM sites, we demonstrate that the tower-based daily averages of surface albedo are comparable for completely overcast and non-overcast conditions. This is consistent with the generally accepted assumption about surface properties being almost temporally invariant within a relatively short period [36]. Note that there is a solar-zenith angle dependence on clear days that agrees with the cloudy-sky albedo when averaged over the day. Therefore, our retrieval originally developed for overcast conditions likely can be adapted for non-overcast conditions, when retrievals are not possible, by interpolating between retrievals on overcast days.

We demonstrate the feasibility of our simple approach for different landscapes with various degrees of heterogeneity. Despite its simplicity, our approach shows promise in routinely obtaining the areal-averaged surface albedo from surface measurements of multi-spectral atmospheric transmission. Since conventional measurements of atmospheric transmission are available at many well-established [37] and temporal (e.g., ARM Mobile Facilities; http://www.arm.gov/sites/amf) sites worldwide, this critical information on spectral surface albedo should be highly beneficial for validating and improving 
large-scale models [38]. Additionally, our retrieval technique can easily be extended to hyperspectral ground-based instruments with fine spectral resolution, such as the SAS-He [39]. In this case, it may be possible to extend spectral surface albedo measurements out to $1700 \mathrm{~nm}$ over selected spectral regions.

\section{Acknowledgments}

This work has been supported by the Office of Biological and Environmental Research (OBER) of the US Department of Energy (DOE) as part of the Atmospheric Radiation Measurement (ARM) Program. The Pacific Northwest National Laboratory (PNNL) is operated by Battelle for the DOE under contract DE-A06-76RLO 1830. The MODIS surface albedo data, with product designation MCD43B3 (https://lpdaac.usgs.gov/products/modis_products_table/mcd43b3; 1-km resolution), are downloaded from the MODIS Reprojection Tool Web Interface (MRTWeb) site (https://mrtweb.cr.usgs.gov/). We greatly appreciate that these data have been made available to us. The image of the Atmospheric Radiation Measurement (ARM) Southern Great Plains Central Facility 60-meter tower is provided courtesy of the U.S. Department of Energy ARM Climate Research Facility. We are grateful to Allison McComiskey and three anonymous reviewers for thoughtful comments.

\section{Author Contributions}

Abstract (Evgueni Kassianov, James Barnard), Introduction (Evgueni Kassianov, James Barnard), Approach (Evgueni Kassianov, James Barnard, Connor Flynn), Areal-averaged and Point Surface Albedo (Evgueni Kassianov, James Barnard, Joseph Michalsky), Data Description (all authors), Results (all authors), Summary (Evgueni Kassianov, James Barnard). Evgueni Kassianov designed the research plan and led manuscript preparation. James Barnard supervised research and manuscript writing. All authors contributed to data analysis.

\section{Conflicts of Interest}

The authors declare no conflict of interest.

\section{Appendix}

\section{A. Sensitivity of the Retrieved Albedo to Assumed Parameters}

Our two-step approach involves assumed values of the surface albedo $A_{415}$ and cloud asymmetry parameter $g_{415}$ at $415 \mathrm{~nm}$ wavelength. To illustrate the sensitivity of the retrieved surface albedo $A_{\lambda}$ at other wavelengths to these assumed values, we re-write Equations (1) and (2) as

$$
\tau_{415}=\alpha_{415} /\left[\left(1-A_{415}\right)\left(1-g_{415}\right)\right]
$$

and

$$
A_{\lambda}=1-\beta_{\lambda} /\left[\tau_{\lambda}\left(1-g_{\lambda}\right)\right]
$$

where parameters $\alpha_{\lambda}$ and $\beta_{\lambda}$ depends on the normalized atmospheric transmission $t_{\lambda}$. 
Using Equations (A1) and (A2) and weak spectrally variability of cloud optical properties ( $\tau_{\lambda}$ and $\left.g_{\lambda}\right)$ we obtain

$$
A_{\lambda} \approx 1-\left(1-A_{415}\right) \beta_{\lambda} / \alpha_{415}
$$

It follows from Equation (A3) that the retrieved surface albedo $A_{\lambda}$ does not depend on the assumed asymmetry parameter $g_{415}$. Also, this equation indicates that $A_{\lambda} \approx 1-\gamma\left(1-A_{415}\right)$, where the parameter $\gamma$ is $\beta_{\lambda} / \alpha_{415}$, and is equal to one for $\lambda=415 \mathrm{~nm}$. This parameter $\gamma$ decreases steadily as $\lambda$ increases (as long as the albedo continues to increase with wavelength). The derivative of Equation (A3) with respect to $A_{415}$ is the sensitivity of $A_{\lambda}$ to changes in $A_{415}$, and is equal to $\gamma$. Therefore, $\Delta A_{\lambda}=\gamma_{\lambda} \Delta A_{415}$, where we have explicitly noted the dependence of $\gamma$ on wavelength. If, for example, we assume that the albedo at $415 \mathrm{~nm}$ is 0.03 , but in actuality is $0.06, \Delta A_{415}=-0.03$, and the calculated albedo will be too low by 0.03 at $415 \mathrm{~nm}$. As the wavelength increases above $415 \mathrm{~nm}$, this error becomes smaller. Fortunately, for the majority of land surface types the surface albedo at 415 is quite small $\left(<0.07\right.$ ) [20]; hence we expect that errors, attributable to the assumption that $A_{415}=0.03$, will be small.

\section{B. Measured and Retrieved Surface Albedo}

Here we provide additional information on the measured tower-based and retrieved areal-averaged surface albedos. This information is beneficial to better understand the differences and similarities between the tower-based measured, retrieved and MODIS-derived surface albedos (Section 5). A comprehensive description of the algorithm for the calculation of MODIS-derived albedos can be found in highly cited papers and technical reports [40,41].

\section{B.1. Tower-Based Measured Albedo: Local}

A downward-looking radiometer mounted on a tower at height, $z$, "sees" the upwelling irradiance, $F^{\uparrow}(z)$,

$$
F^{\uparrow}(z)=\int_{0}^{2 \pi} \int_{0}^{1} I^{\uparrow}(z, \mu, \phi) \mu d \mu d \phi
$$

where $I^{\uparrow}$ is the upwelling radiance at the height $z, \phi$ is the azimuth angle, and $\mu$ is the cosine of the angle, $\theta$, between the vertical and the direction from whence the radiance emanates. For the sake of simplicity, we assume that $I^{\uparrow}$ does not depend on either $\phi$ or $\mu$. The fraction of irradiance that is seen between the angles of $0^{\circ}$ (the vertical) and $\theta_{0}$ is therefore

$$
\frac{\int_{\mu_{0}}^{1} \mu d \mu}{\int_{0}^{1} \mu d \mu}=1-\mu_{0}^{2}
$$

where $\mu_{0}=\cos \theta_{0}$. For $\theta_{0}$ equal to $72^{\circ}, 90 \%$ of the upwelling irradiance is captured. Assuming that this angle represents an effective field of view of the downward-looking radiometer, we notice that the area "seen" by the radiometer is $=z \times \operatorname{tg}\left(72^{\circ}\right)=3.1 z$, where $\operatorname{tg}\left(\theta_{0}\right)$ is tangent of the angle $\theta_{0}$. Thus, 
if the radiometer is mounted at a height of $10 \mathrm{~m}$, it effectively "sees", at the surface, a circle of radius $31 \mathrm{~m}$. A radius of this magnitude describes a local measurement.

\section{B.2. Retrieved Albedo: Areal-Averaged}

An upward-looking radiometer at the surface, under a thick cloud deck, "sees" both radiance from the sun-scattered through the cloud to the radiometer-and radiance that has been reflected off the Earth's surface, has hit the cloud deck, and is bounced back to the radiometer. In a similar vein to the argument given above, a given point on a cloud will view radiance from the area of circle on the surface of earth with a radius $3.1 h$, where $h$ is the cloud height. For a cloud height of $1 \mathrm{~km}$, this radius is about $3 \mathrm{~km}$. Assuming, for the sake of argument, that the radiometer only senses radiance from directly above, the reflected component of the radiance comes from this area. However, this area represents the minimum area because the radiometer "sees" radiances from other points on the cloud, which are not directly above the radiometer. In turn, these points will capture photons from locations greater than $3 \mathrm{~km}$ away from the radiometer. Therefore the cloud-reflected component "seen" by the radiometer represents a large area that is significantly greater-at least three times-than the cloud height.

To outline our approach more formally, we apply the conventional 1D RT approximation introduced previously by Barker and Marshak [42]. This approximation describes assumed 1D conditions: an overcast homogeneous cloud layer with cloud optical depth $(\tau)$ and uniform land surface with albedo $(A)$. According to this approximation, the radiance measured at surface can be written as a sum of two terms

$$
I^{\downarrow}(z=0) \approx I_{\tau}^{\downarrow}(z=0)+I_{\tau, A}^{\downarrow}(z=0)
$$

where the second term is proportional to $F^{\uparrow}(z=h) \rho_{\tau}$, where $\rho_{\tau}$ is the cloud-base reflectance. The subscript symbols ( $\tau$ and $A$ ) define dependence of these two radiances on cloud optical depth and surface albedo. For the sake of clarity, we skip their dependence on zenith $\theta$ and azimuth $\phi$ angles. For an optically thick cloud layer $(\tau>5)$, the cloud reflectance can be approximated as Lambertian and, therefore, the second term is proportional to $F^{\uparrow}(z=h) \rho_{\tau} / \pi$. Note that the upwelling flux $F^{\uparrow}(z=h)$ depends on the surface albedo and combines contributions from an area with radius proportional to the cloud base height, $h$. For typical cloud base height $(h \sim 1 \mathrm{~km})$, the dominant contribution to $F^{\uparrow}(z=h)$ comes from a large area (i.e., as mentioned above, at least $3 \mathrm{~km}$ for $h$ equal to $1 \mathrm{~km}$ ).

Using Equation (A6), we define the downwelling irradiance measured by a ground-based upward-looking radiometer as

$$
F^{\downarrow}(z=0) \approx F_{\tau}^{\downarrow}(z=0)+F_{\tau, A}^{\downarrow}(z=0)
$$

The relative contribution of the second term $F_{\tau, A}^{\downarrow}(z=0)$ to the measured irradiance $F^{\downarrow}(z=0)$ is small and substantial, for "dark" and "bright" surfaces, respectively. Recall that the same surface can be considered as a "dark" or "bright" depending upon wavelength (e.g., vegetated surface is "dark" at $415 \mathrm{~nm}$ wavelength, while it is "bright" at $870 \mathrm{~nm}$ wavelength). Equation (A7) illustrates the general idea of our two-step approach described in Section 2. Since the second term $F_{\tau, A}^{\downarrow}(z=0)$ is 
proportional to the upwelling flux $F^{\uparrow}(z=h)$, which encompasses a contribution from a large area ( $\sim 3 \mathrm{~km}$ and greater), our approach allows one to retrieve areal-averaged albedo.

\section{Multi-Year Time Series of Albedo}

Here we provide multi-year time series of the tower-based measured, retrieved and MODIS-derived albedos at the ARM sites. Figure A1 is an extended version of Figure 5.

Figure A1. Time series of the tower-measured 10-m (a) and 25-m (b) surface albedo at the ARM site, their weighted average (c); MODIS-derived (d) and MFRSR-retrieved areal-averaged surface albedo (e). Black, red, green, blue and orange colors define the surface albedo values $(\mathrm{a}-\mathrm{c}, \mathrm{e})$ at five MFR/MFRSR wavelengths $(415,500,615,673$ and $870 \mathrm{~nm}$ ). Magenta, yellow, violet and dark yellow colors define the surface albedo values (d) at four MODIS wavelengths (470, 560, 670 and $860 \mathrm{~nm}$ ); (e) Solid lines (red, green, blue and orange) represent the smoothed versions of MFRSR-retrieved surface albedos at four wavelengths $(500,615,673$ and $870 \mathrm{~nm})$ (boxcar averaging; 5 points).
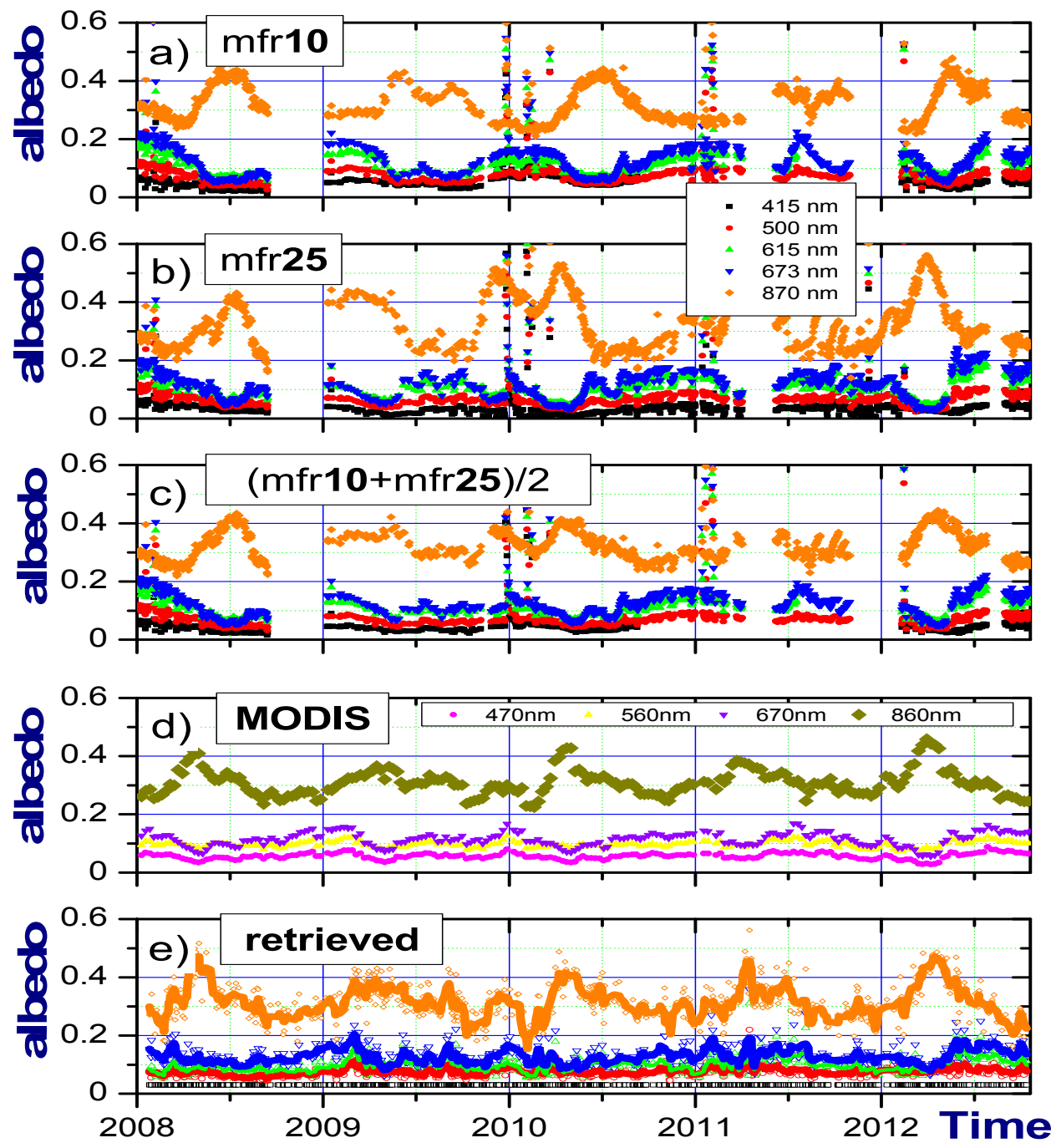


\section{References}

1. Myhre, G.; Myhre, A. Uncertainties in radiative forcing due to surface albedo changes caused by land-use changes. J. Clim. 2003, 16, 1511-1524.

2. Park, S.; Wu, X. Effects of surface albedo on cloud and radiation processes in cloud-resolving model simulations. J. Atmos. Sci. 2010, 67, 1474-1491.

3. Michalsky, J.; Min, Q.; Barnard, J.; Marchand, R.; Pilewski, P. Simultaneous spectral albedo measurements near the Atmospheric Radiation Measurement Southern Great Plains (ARM SGP) central facility. J. Geophys. Res.: Atmos. 2003, doi:10.1029/2002JD002906.

4. Michalsky, J.J.; Hodges, G.; Field, B. Measured spectral albedo-Four years of data from the Western U.S. Prairie. J. Geophys. Res.: Atmos. 2013, 118, 813-825.

5. Schaaf, C.B.; Gao, F.; Strahler, A.H.; Lucht, W.; Li, X.W.; Tsang, T.; Strugnell, N.C.; Zhang, X.Y.; Jin, Y.F.; Muller, J.P.; et al. First operational BRDF, albedo nadir reflectance products from MODIS. Remote Sens. Environ. 2002, 83, 135-148.

6. Román, M.O.; Gatebe, C.K.; Shuai, Y.M.; Wang, Z.S.; Gao, F.; Masek, J.G.; He, T.; Liang, S.L.; Schaaf, C.B. Use of in situ and airborne multiangle data to assess MODIS- and Landsat-based estimates of directional reflectance and albedo. IEEE Trans. Geosci. Remote Sens. 2013, 51, 1393-1404.

7. Robinson, G.D. Some observations from aircraft of surface albedo and the albedo and absorption of cloud. Theor. Appl. Climatol. 1958, 9, 28-41.

8. Coddington, O.; Schmidt, K.S.; Pilewskie, P.; Gore, W.J.; Bergstrom, R.W.; Román, M.; Redemann, J.; Russell, P.B.; Liu, J.; Schaaf, C.C. Aircraft measurements of spectral surface albedo and its consistency with ground-based and space-borne observations. J. Geophys. Res.: Atmos. 2008, doi:10.1029/2008JD010089.

9. Liang, S.; Fang, H.; Chen, M.; Shuey, C.J.; Walthall, C.; Daughtry, C.; MOrisette, J.; Schaaf, C.; Strahler, A. Validating MODIS land surface reflectance and albedo products: Methods and preliminary results. Remote Sens. Environ. 2002, 83, 149-162.

10. Lyapustin, A.I. Atmospheric and geometrical effects on land surface albedo. J. Geophys. Res.: Atmos. 1999, 104, 4127-4143.

11. Pinty, B.; Taberner, M.; Haemmerle, V.R.; Paradise, S.R.; Vermote, E.; Verstraete, M.M.; Gobron, N.; Widlowski, J.-L. Global-scale comparison of MISR and MODIS land surface albedos. J. Clim. 2011, 24, 732-749.

12. Cescatti, A.; Marcolla, B.; Vannan, S.K.S.; Pan, J.Y.; Román, M.O.; Yang, X.; Ciais, P.; Cook, R.B.; Law, B.E.; Matteucci, G.; et al. Intercomparison of MODIS albedo retrievals and in situ measurements across the global FLUXNET network. Remote Sens. Environ. 2012, 121, 323-334.

13. Lattanzio, A.; Schulz, J.; Matthews, J.; Okuyama, A.; Theodore, B.; Bates, J.J.; Knapp, K.R.; Kosaka, Y.; Schüller, L. Land surface albedo from geostationary satellites: A multiagency collaboration within SCOPE-CM. Bull. Am. Meteorol. Soc. 2013, 94, 205-214.

14. Leontieva, E.; Stamnes, K. Remote sensing of cloud optical properties from ground-based measurements of transmittance: A feasibility study. J. Appl. Meteorol. 1996, 35, 2011-2022. 
15. McBride, P.J.; Schmidt, K.S.; Pilewskie, P.; Kittelman, A.S.; Wolfe, D.E. A spectral method for retrieving cloud optical thickness and effective radius from surface-based transmittance measurements. Atmos. Chem. Phys. 2011, 11, 7235-7252.

16. Ricchiazzi, P.; Gautier, C.; Lubin, D. Cloud scattering optical depth and local surface albedo in the Antarctic: Simultaneous retrieval using ground-based radiometry. J. Geophys. Res.: Atmos. 1995, 100, 21091-21104.

17. Barnard, J.C.; Long, C.N.; Kassianov, E.I.; McFarlane, S.A.; Comstock, J.M.; Freer, M.; Farquhar, G. Development and evaluation of a simple algorithm to find cloud optical depth with emphasis on thin ice clouds. Open Atmos. Sci. J. 2008, 2, 46-55.

18. Slingo, A. A GCM parameterization for the shortwave radiative properties of water clouds. Atmos. Sci. 1989, 46, 1419-1427.

19. Kokhanovsky, A. Cloud Optics; Springer: Dordrecht, The Netherland, 2006.

20. Feister, W.; Grewe, R. Spectral albedo measurements in the UV and visible region. Photochem. Photobiol. 1995, 62, 736-744.

21. Jin, Y.; Schaaf, C.B.; Woodstock, C.E.; Gao, F.; Li, X.; Strahler, A.H.; Lucht, W.; Liang, S. Consistency of MODIS surface bidirectional reflectance distribution function and albedo retrievals: 2. Validation. J. Geophys. Res.: Atmos. 2003, doi:10.1029/2002JD002804.

22. Liu, J.; Schaaf, C.; Strahler, A.; Jiao, Z.; Shuai, Y.; Zhang, Q.; Roman, M.; Augustine, J.A.; Dutton, E.G. Validation of Moderate Resolution Imaging Spectroradiometer (MODIS) albedo retrieval algorithm: Dependence of albedo on solar zenith angle. J. Geophys. Res.: Atmos. 2009, doi:10.1029/2008JD009969.

23. Liou, K.-N. An Introduction to Atmospheric Radiation; Academic Press: Amsterdam, The Netherland/Boston, MA, USA, 2002; p. 583.

24. Kokhanovsky, A.; McBride, P.J.; Schmidt, K.S.; Pilewskie, P. The determination of cloud optical thickness and effective particle size from measurements of transmitted solar diffuse light. IEEE Geosci. Remote Sens. Lett. 2013, 10, 1512-1516.

25. Barnard, J.; Long, C.N. A simple empirical equation to calculate cloud optical thickness using shortwave broadband measurements. J. Appl. Meteorol. 2004, 43, 1057-1065.

26. Hu, Y.X.; Stamnes, K. An accurate parameterization of the radiative properties of water clouds suitable for use in climate models. J. Clim. 1993, 6, 728-742.

27. Sengupta, M.; Clothiaux, E.E.; Ackerman, T.P. Climatology of warm boundary layer clouds at the ARM SGP site and their comparison to models. J. Clim. 2004, 17, 4760-4782.

28. Dong, X.; Minnis, P.; Xi, B._A climatology of midlatitude continental clouds from the ARM SGP Central Facility: Part I: Low-level cloud macrophysical, microphysical, and radiative properties. J. Clim. 2005, 18, 1391-1410.

29. Wang, K.; Liang, S.; Schaaf, C.L.; Strahler, A.H. Evaluation of Moderate Resolution Imaging Spectroradiometer land surface visible and shortwave albedo products at FLUXNET sites. J. Geophys. Res.: Atmos. 2010, doi:10.1029/2009JD013101.

30. Rowe, C.M. Incorporating landscape heterogeneity in land surface albedo models. J. Geophys. Res.: Atmos. 1993, 98, 5037-5043. 
31. Yang, F.; Mitchell, K.; Hou, Y.-T.; Dai, Y.; Zeng, X.; Wang, Z.; Liang, X.-Z. Dependence of land surface albedo on solar zenith angle: Observations and model parameterization. J. Appl. Meteor. Climatol. 2008, 47, 2963-2982.

32. Jäkel, E.; Wendisch, M.; Mayer, B. Influence of spatial heterogeneity of local surface albedo on the areal-averaged surface albedo retrieved from airborne irradiance measurements. Atmos. Measur. Tech. 2013, 6, 527-537.

33. Long, C.N.; Ackerman, T.P.; Gaustad, K.L.; Cole, J.N.S. Estimation of fractional sky cover from broadband shortwave radiometer measurements. J. Geophys. Res.: Atmos. 2006, doi:10.1029/ 2005JD006475.

34. McFarlane, S.A.; Gaustad, K.L.; Mlawer, E.J.; Long, C.N.; Delamere, J. Development of a high spectral resolution surface albedo product for the ARM Southern Great Plains central facility. Atmos. Meas. Tech. 2011, 4, 1713-1733.

35. Cook, D.R. Tower Temperature and Humidity Sensors. Available online: https://www.wmo.int/pages/ prog/gcos/documents/gruanmanuals/Z_instruments/twr_handbook.pdf (accessed on 13 August 2014)

36. Lyapustin, A.I.; Wang, Y.; Laszlo, I.; Hilker, T.; Hall, F.G.; Sellers, P.J.; Tucker, C.J.; Korkin, S.V. Multi-angle implementation of atmospheric correction for MODIS (MAIAC): 3. Atmospheric correction. Remote Sens. Environ. 2012, 127, 385-393.

37. Augustine, J.A.; Cornwall, C.R.; Hodges, G.B.; Long, C.N.; Medina, C.I.; DeLuisi, J.J. An automated method of MFRSR calibration for aerosol optical depth analysis with application to an Asian dust outbreak over the United States. J. Appl. Meteor. 2003, 42, 266-278.

38. Roesch, A.; Wild, M.; Pinker, R.; Ohmura, A. Comparison of spectral surface albedos and their impact on the general circulation model simulated surface climate. J. Geophys. Res.: Atmos. 2002, doi:10.1029/2001JD000809.

39. Barnard, J.; Flynn, C.J.; Ermold, B. The Shortwave Solar Spectroradiometer-Hemispheric: A new ARM instrument for aerosol and cloud research. In Proceedings of the AGU Fall Meeting, San Francisco, CA, USA, 3-7 December 2012.

40. Lucht, W.; Schaaf, C.B.; Strahler, A.H. An Algorithm for the retrieval of albedo from space using semiempirical BRDF models. IEEE Trans. Geosci. Remote Sens. 2000, 38, 977-998.

41. MODIS BRDF/Albedo Product: Algorithm Theoretical Basis, Document Version 5.0. Available online: http://modis.gsfc.nasa.gov/data/atbd/atbd_mod09.pdf (accessed on 13 August 2014)

42. Barker, H.W.; Marshak, A. 2001: Inferring optical depth of broken clouds above green vegetation using surface solar radiometric measurements. J. Atmos. Sci. 2001, 58, 2989-3006.

(C) 2014 by the authors; licensee MDPI, Basel, Switzerland. This article is an open access article distributed under the terms and conditions of the Creative Commons Attribution license (http://creativecommons.org/licenses/by/3.0/). 